\title{
Molecular mechanism and targeted therapy of Hsp90 involved in lung cancer: New discoveries and developments (Review)
}

\author{
BIAOXUE RONG $^{1}$ and SHUANYING YANG ${ }^{2}$ \\ ${ }^{1}$ Department of Oncology, First Affiliated Hospital, Xi'an Medical University; \\ ${ }^{2}$ Department of Respiratory Medicine, Second Affiliated Hospital, \\ Xi'an Jiaotong University, Xi'an, Shaanxi, P.R. China
}

Received March 11, 2017; Accepted June 13, 2017

DOI: 10.3892/ijo.2017.4214

\begin{abstract}
The exploration of the molecular mechanisms and signaling pathways on lung cancer is very important for developing new strategies of diagnosis and treatment to this disease, such as finding valuable lung cancer markers and molecularly targeted therapies. Previously, a number of studies disclose that heat shock protein 90 (Hsp90) is upregulated in cancer cells, tissues and serum of lung cancer patients, and its upregulation intimately correlates with the occurrence, development and outcome of lung cancer. On the contrary, inhibition of Hsp90 can suppress cell proliferation, motility and metastasis of lung cancer and promote apoptosis of lung cancer cells via complex signaling pathways. In addition, a series of Hsp90 inhibitors have been investigated as effective molecular targeted therapy tactics fighting against lung cancer. This review, systematically summarizes the role of Hsp90 in lung cancer, the molecular mechanisms and development of anti-Hsp90 treatment in lung cancer.
\end{abstract}

\section{Contents}
1. Introduction
2. Molecular structure and function domain of Hsp90
3. Co-chaperons and client proteins of Hsp90
4. Expression of Hsp90 in lung cancer
5. Biological functions of Hsp90 in lung cancer
6. Hsp90-dependent radiosensitization in treatment of lung cancer
7. Hsp90 and drug resistance of lung cancer

Correspondence to: Dr Biaoxue Rong, Department of Oncology, First Affiliated Hospital, Xi'an Medical University, 8 Fenghao West Road, Xi'an, Shaanxi 710077, P.R. China

E-mail: research568rbx@yeah.net

Key words: lung cancer, Hsp90, expression, drug target, molecular targeted therapy
8. Clinical research on Hsp90 inhibitors for treating lung cancer

9. Perspective and limitation

10. Conclusion

\section{Introduction}

With the development of tumor molecular biology, progress of the detection and treatment of cancer has led to an impressive reduction in both mortality and morbidity. However, cancer still remains one of the most clinically challenging diseases (1). Today, it is believed that systemic chemotherapy improves the survival and quality of life of patients with advanced stage cancer, and improved the outcome of first-line therapy for advanced and metastatic cancer have primarily focused on the addition of targeted agents to platinum-based two-drug regimens (2). Medical studies suggest that understanding the molecular mechanism of tumors is critical for improving the diagnosis and treatment. Especially, the level of certain protein expression is associated with the prognosis and treatment of malignant tumors (3). Heat shock protein 90 (Hsp90) accounts for 1-2\% of the amounts of cellular proteins under non-stressed conditions. However, it contents would go up approximately twice during environmental stress (4). Hsp90 performs a series of biological functions via complicated signals regulation by combining and disaggregation of ATP, and various client proteins and co-chaperones of Hsp90 are implicated in this process (5). Human Hsp90 includes four isoforms: Hsp90 $\alpha$ and $\beta$ (cytosolic isoforms), TRAP1 (in mitochondria) and Grp94 (in endoplasmic reticulum) (6). Hsp90 $\beta$ (Hsp90AB1) is regarded as a constitutive expression while Hsp90 $\alpha$ (Hsp90AA1) as an inducible expression, it is proved that they have $86 \%$ amino acid sequence identity (7). Hsp90 has been found as a critical regulator of cell proliferation, development, mobility and metastasis in malignant tumors, which facilitates maturation and activation of oncogenic proteins, including many kinases and transcription regulatory factors (8). Also, Hsp90 exerts anti-apoptotic activity and affects growth processes tumor cells, and overexpression of Hsp90 has been obviously associated with drug resistance 


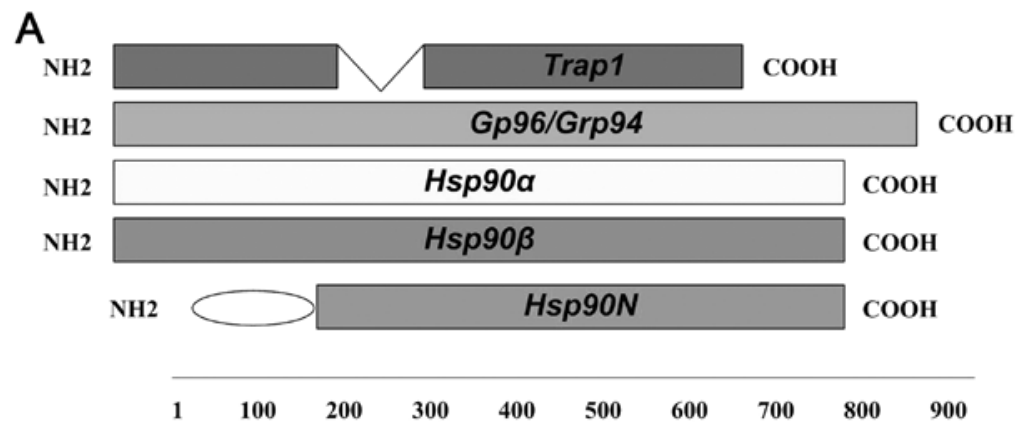

B
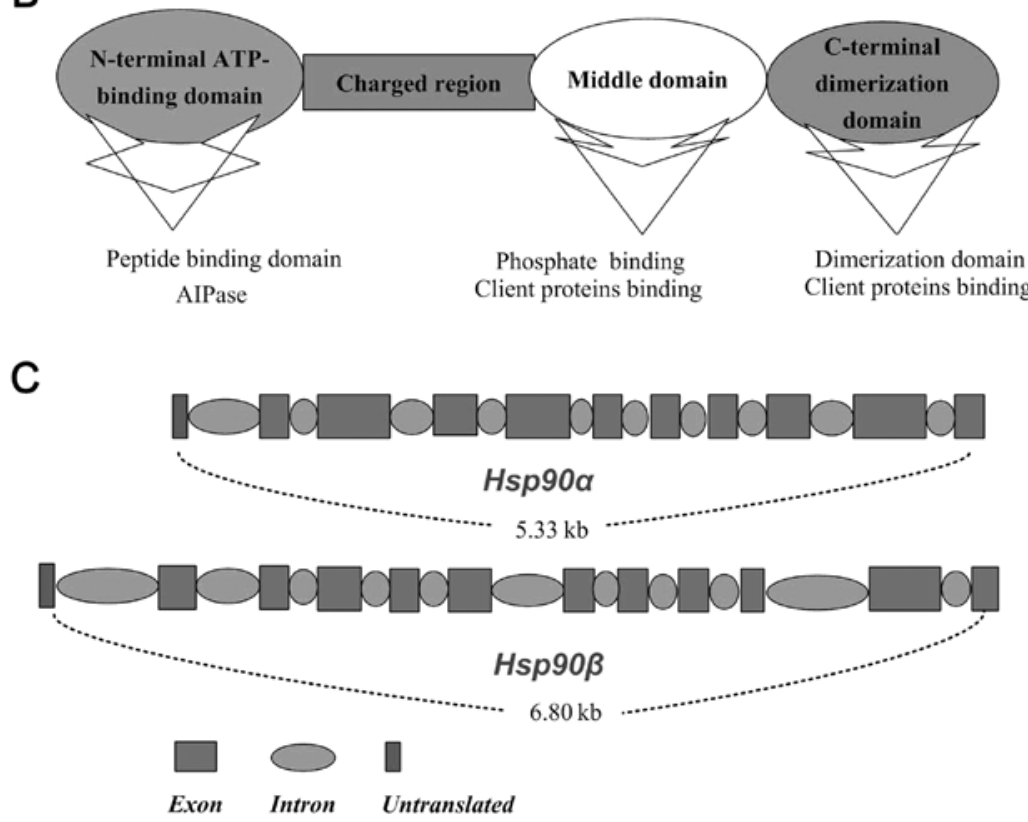

Figure 1. Molecular structure and function domain of Hsp90. (A) Hsp90a, Hsp90ß, gp96 and the TRAP1 are four members of Hsp90 family 4. (B) Each protomer of Hsp90 comprises three regions, ATP-binding domain (N-domain), middle domain (M-do-main), and C-terminal dimerization domain (C-do-main); the 25-kDa N-terminal of Hsp90 is relatively conserved, which is linked with $55 \mathrm{kDa}$ C-terminal domains by a charged linker region; the $\mathrm{N}$-terminal domain of Hsp90 combined with ATP is intimately tied up with a middle domain via an unstructured charged linker, and the C-terminal domain; the middle domain of Hsp90 is $\sim 35 \mathrm{kDa}$, and a binding site for client proteins and nuclear localization signal, which is implicated in recognising of collaborating proteins and adjusting the activation molecular chaperones. (C) Hsp90 $\alpha$ and $\mathrm{Hsp} 90 \beta$, exist as a result of the duplication of the original gene and share $86 \%$ homology; the chromosome 14q32.33 encodes the Hsp90 $\alpha$, while Hsp90 $\beta$ is located at 6p21. Hsp90-coding genes include intron sequences and the second exon is the region of translational initiation of both $\mathrm{Hsp} 90 \alpha$ and Hsp90 3 . Hsp90, heat shock protein 90; TRAP1, TNF receptor associated protein 1; ATP, adenosine-triphosphate.

and survival time of tumor patients (9). Previous studies show that Hsp90 is highly expressed in specimens of lung cancer and are associated with poor post-surgical survival time and lymphatic metastasis of lung cancer patients (10-13) indicating that upregulation of Hsp90 potentially facilitates proliferation and metastasis of lung cancer. However, anti-Hsp90 (Hsp90 inhibitors) studies have demonstrated that downregulation and function disruption of Hsp90 inhibits cell proliferation, motility and metastasis, and induces apoptosis of lung cancer cells $(11,12,14)$. Here, we reviewed new findings on the role of Hsp90 in lung cancer, including the mechanisms and signaling pathways, the pre-clinical results of Hsp90 inhibition (14).

\section{Molecular structure and function domain of Hsp90}

As a homodimeric protein of $\sim 90 \mathrm{kDa}$, Hsp90 performs complicated biological functions reacting with many collaborating proteins (co-chaperons and clients proteins of Hsp90) (15). As shown in Fig. 1A, Hsp90 $\alpha$, Hsp90 $\beta$, gp96 and the TRAP1 are four members of Hsp90 family (7). Different members of Hsp90 family present the same action pattern but binding to specially appointed clients proteins, which depends in part on their locations and distribution within the different cells (16). Each protomer of Hsp90 comprises three regions, ATP-binding domain (N-domain), middle domain (M-domain), and C-terminal dimerization domain (C-domain) (17) (Fig. 1B). Constructively, the $25-\mathrm{kDa}$-terminal of $\mathrm{Hsp} 90$ is relatively conserved, which is linked with $55 \mathrm{kDa}$ C-terminal domains by a charged linker region and middle domain (16) (Fig. 1B). The middle domain of Hsp90 is $\sim 35 \mathrm{kDa}$, has been investigated as a binding site for client proteins and nuclear localization signal, which is implicated in recognising of collaborating proteins and adjusting the activation molecular chaperones (18) (Fig. 1B). Hsp90 exerts relevant functions via binding and hydrolysis of ATP like a molecular clamp, which facilitates the combining and dissociation of its client proteins (19) (Fig. 1B). The important two members of Hsp90, Hsp90 $\alpha$ and Hsp90 $\beta$, exist as a result of the duplication of the 
A

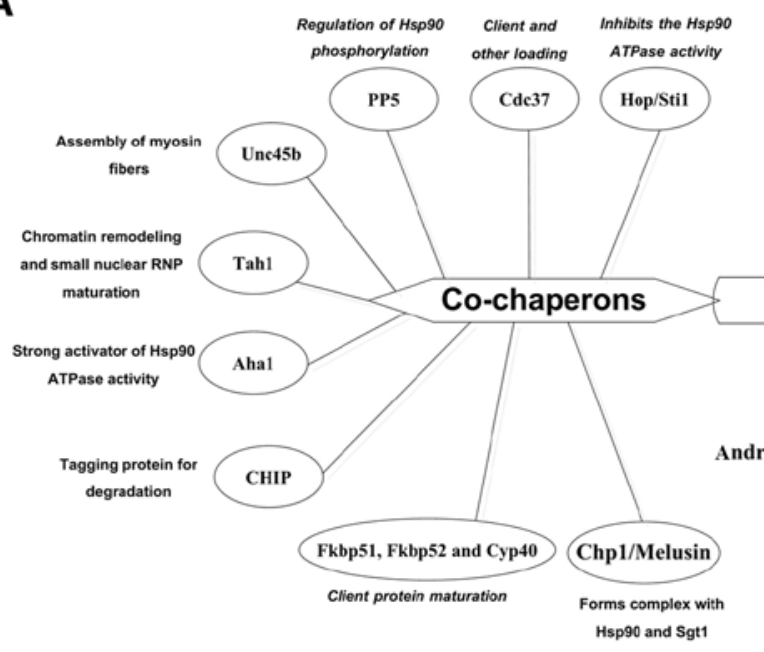

B
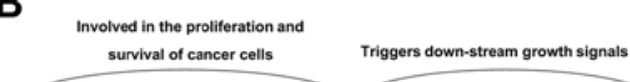

ErbB2/HER2, TGF receptor I and II Src, Yes, Fes, Fps, Abl and Ick

ErbB2/HER2, TGF receptor I and II Src, Yes, Fes, Fps, Abl and Lek

Rafl and B-Raf Proliferation signals from the

Cdk4 and Cdk6 Regulate the cell cycle machinery

HSP90

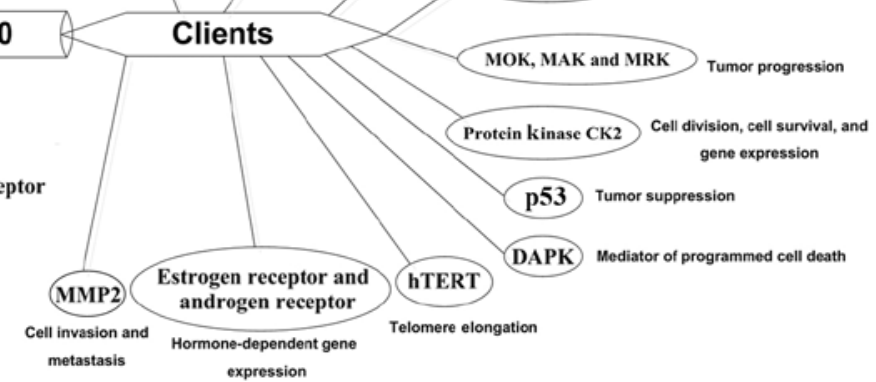

Figure 2. Co-chaperons and client proteins of Hsp90. (A) More than 20 different proteins regulate the activity and function of Hsp90, which are known as co-chaperones and these proteins regulate the chaperoning function of Hsp90 by activating and inhibiting the activity of Hsp90 ATPase and sometimes by recruiting the specific client proteins; some key co-chaperones include Hop/Sti1, Cdc37, p23/Sba1, PP5, Fkbp51, Fkbp52, Cyp40, Unc45b, Tah1, Aha1 and CHIP. (B) The specific co-chaperones of Hsp90 could have a specific intimate relationship with one, even more than one client protein and participate in a series of specific biological reactions; some key co-chaperones include ErbB2/HER2, IGF-I and TGF receptor I and II; the members of Src family, Yes, Fes, Fps, Abl and Lck; ERK1, ERK2, Raf1, B-Raf, Cdk4, Cdk6, hTERT, MMP2, p53, CK2, MOK, MAK, MRK, DAPK. Hsp90, heat shock protein 90; ATPase, adenylpyrophosphatase; Hop/Sti1, a co-chaperone adaptor protein for Hsp90; Cdc37, cell division cycle 37; p23/Sba1, the protein encoded by the PTGES3 gene; PP5, protein phosphatase 5; Fkbp51 and Fkbp52, Hsp90-associated human peptidyl prolyl cis/trans isomerases; Cyp40, cyclophilin 40; Unc45b, unc45 myosin chaperone b; Tah1, TPR7-containing protein associated with Hsp90; Aha1, activator of Hsp90 ATPase; CHIP, carboxyl-terminus of the Hsp70 interacting protein; ErbB2/HER2, human epidermal growth factor receptor-2; IGF-I, insulin-like growth factor 1; TGF, transforming growth factor; Yes, Fes, Fps, Abl and Lck, some of Src family tyrosine kinases; ERK, extracellular-signal-regulated kinase; Raf, rapidly accelerated fibrosarcoma gene; Cdk, cyclin-dependent kinase; hTERT, human telomerase reverse transcriptase; MMP2, matrix metalloproteinase-2; p53, tumor suppressor p53; CK2, casein kinase 2; MOK, MAK and MRK, MAPK-related protein kinases; DAPK, death associated protein kinase.

original gene and share $86 \%$ homology (20). In humans, the chromosome $14 q 32.33$ encodes the Hsp90 $\alpha$, while Hsp90 $\beta$ is located at 6p21. Hsp90-coding genes include intron sequences and the second exon is the region of translational initiation of both Hsp90 $\alpha$ and Hsp90ß (7) (Fig. 1C).

\section{Co-chaperons and client proteins of Hsp90}

Co-chaperons of Hsp90. The discovery and structural characterization of the ATP-binding site in the N-terminal domain of HSP90, made it possible to determine the degree to which the ATPase activity of HSP90 contributed to the essential biological functions of HSP90 as a molecular chaperone. There are more than 20 different proteins that regulate the activity and function of Hsp90, which are known as co-chaperones (Fig. 2A). Of them, Hop/Stil inhibits the activity of Hsp90 ATPase and recruits steroid hormone receptor to Hsp90 (21,22). Cdc37 helps the loading of other co-chaperones of Hsp90 (18), p23/Sba1 inhibits the ATPase activity of Hsp90 and also promotes the maturation of client proteins $(22,23)$. PP5 stabilises the status of Hsp90 phosphorylation promoting the efficient processing of client proteins $(24,25)$. Human peptidyl prolyl cis/trans isomerases, Fkbp51, Fkbp52 and Cyp40 improve the client protein maturation of Hsp90 (26). Unc45b forms a stable complex with Hsp90 and selectively combines the myosin motor domain, and promotes motor domain folding (27). Together with the Tah1 cofactor, Hsp90 stabilize Pih1/Nop17 and increases the chromatin remodeling and small nuclear ribonucleoprotein maturation (28). Aha1 induces Hsp90 rearrangements that speeds up the conforma- tional cycle, which defines a controlled progression through distinct intermediates (29). Co-chaperones of Hsp90 are also involved in other physiological processes, such as mitochondrial/chloroplast protein import, nuclear migration and melanoma progression (30).

Client proteins of Hsp90. The client proteins of Hsp90 have been found to be related to a wide aspects of physiological procedures including the regulation of cell cycle, communication of cell signals and regulation of cell transcription and post-transcriptional adjustment (Fig. 2B). Hsp90 plays a critical role in the function and stability of ErbB2/HER 2 by binding to IGF-I and TGF receptor I and II $(18,31,32)$. The members of Src family, Yes, Fes, Fps, Abl and Lck, have been shown to be related to the exertion of Hsp90 function, which activate the cascade reaction of downstream molecules $(18,33,34)$. Two proteins of MAPK pathway, ERK1 and ERK2 regulate the growth of cells by phosphorylating many kinds of substrates within the nucleus. In addition, Hsp90 correlates with the structure and function of Raf-1 and B-Raf by interacting with Cdc37 $(18,35,36)$. Clearly, the activity of CK2 depends upon the appearance of Hsp90 $(12,37)$, estrogen and androgen receptors, require the assistance of Hsp90 to enable the steroid hormone ligand to bind (16). Inhibiting Hsp90 results in the proteolysis of hTERT, which affects the function of hTERT $(38,39)$. Downregulation of Hsp90 reduces the expression of MMP9 and protects the MMP2 from degradation in malignant cells $(40,41)$. Also, p53 interacts with Hsp90 in a relatively folded state, which may be chalked up to the destabilization by Hsp90 $(42,43)$. Some Hsp90 client proteins, 


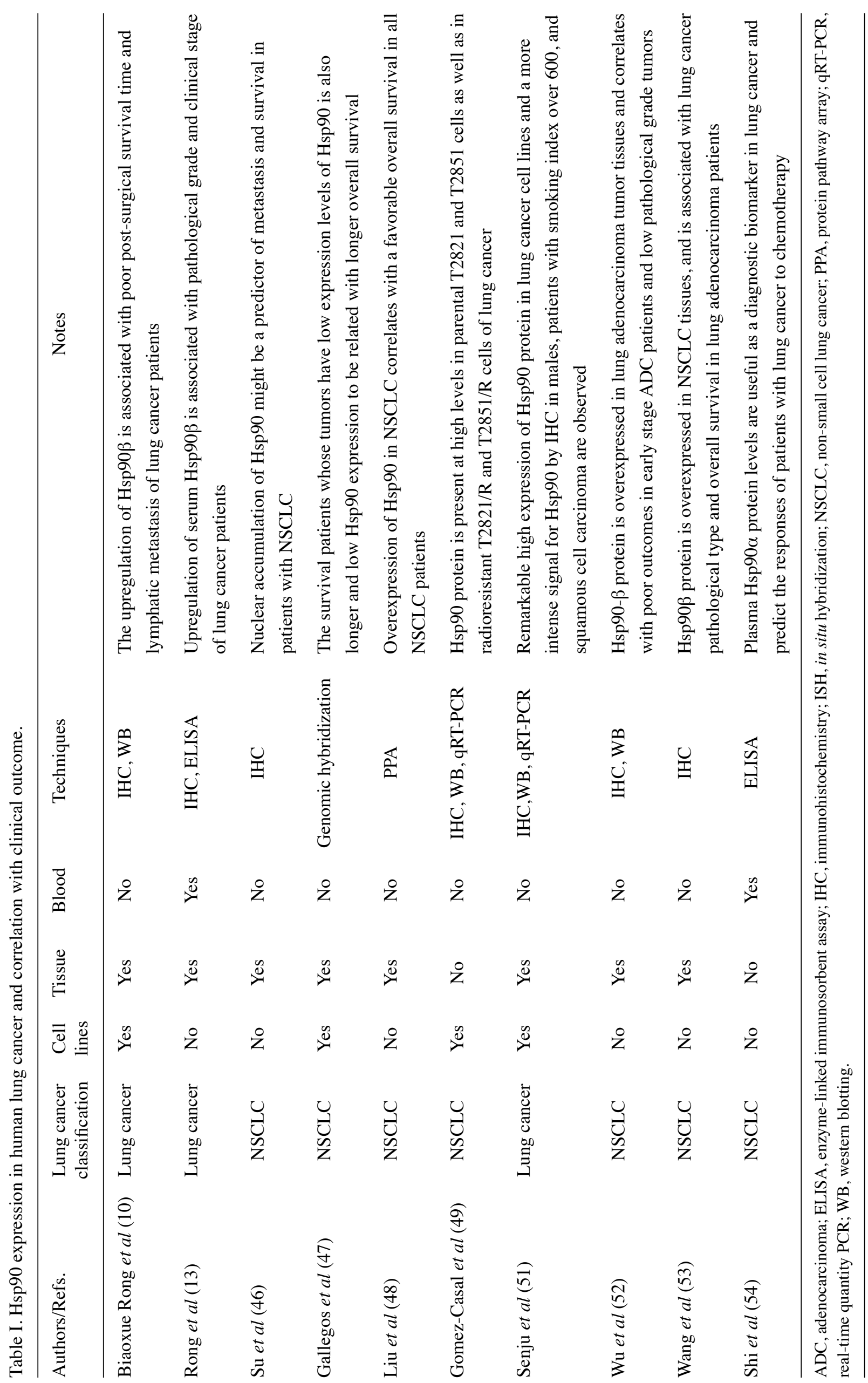




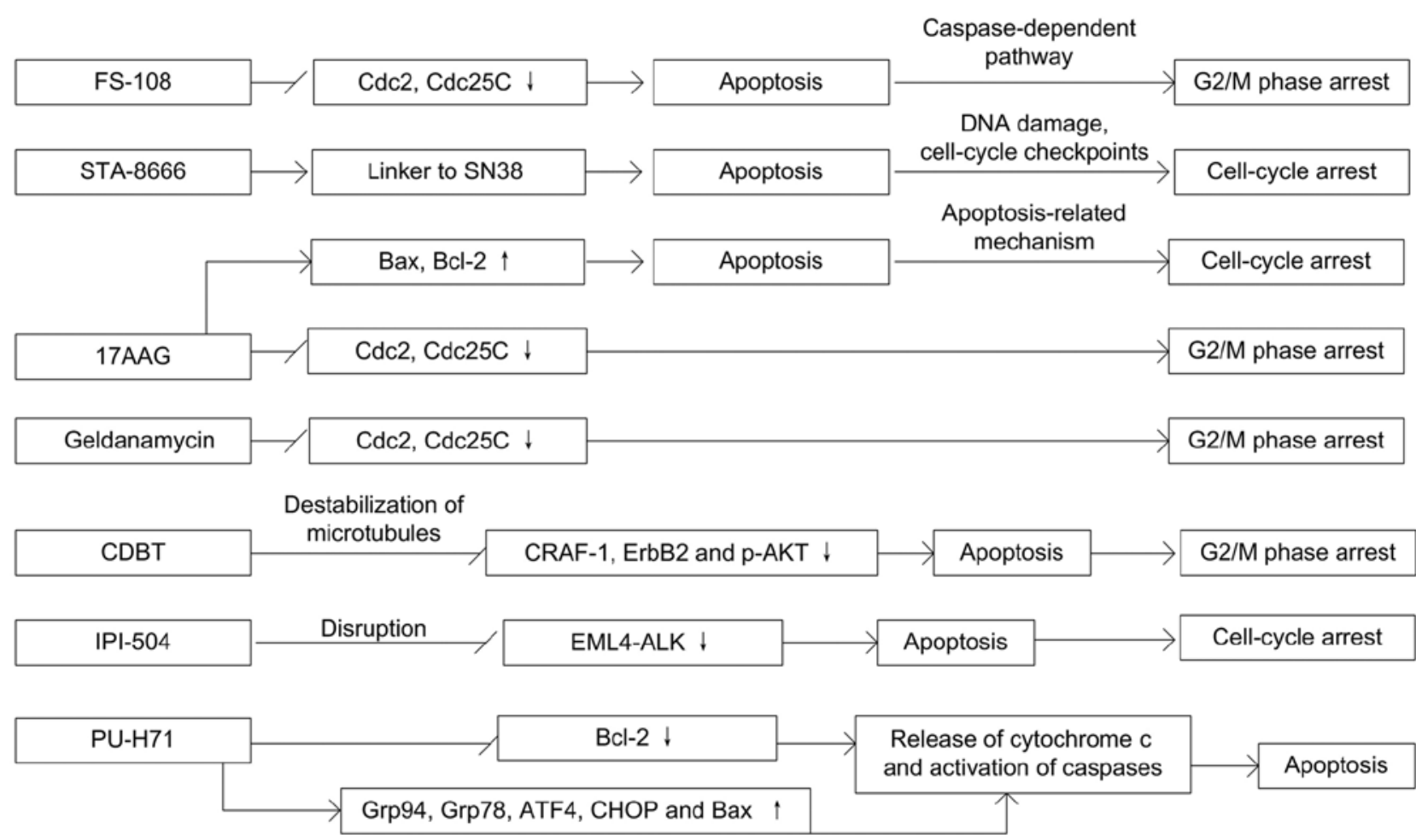

Figure 3. Influence of Hsp90 on the cell cycle regulation and cell apoptosis. Inhibition of Hsp90 induces G2/M phase arrest of lung cancer cells by reducing the expression of $\mathrm{Cdc} 2$ and $\mathrm{Cdc} 25 \mathrm{C}$ and promotes apoptosis via a caspase-dependent pathway; inhibition of Hsp90 induces an effective cell cycle arrest, which is associated with DNA damage and cell cycle checkpoints, and apoptosis by regulating the expression of Bax and Bcl-2. Inhibition of Hsp90 causes the destabilization of microtubules and degradation of CRAF-1 and ERBB2 and phosphorylated AKT, leading to cell cycle arrest at the G2/M phase and reinforcement of apoptosis. Hsp90 inhibition leads to disruption of EML4-ALK and induces growth arrest and apoptosis in lung cancer cells. Hsp90 inhibition upregulates Grp94, Grp78, ATF4 and CHOP and induces apoptosis of lung cancer cells by downregulation of Bcl-2, upregulation of Bax, release of cytochrome $c$ and activation of caspases. Hsp90, heat shock protein 90; Cdc2, cell division cycle 2; Cdc25C, cell division cycle 25C; DNA, deoxyribonucleic acid; Bax, bcl-2-like protein 4; Bcl-2, B-cell lymphoma-2; CRAF-1, threonine protein kinase; ERBB2, human epidermal growth factor receptor-2; AKT, anaplastic lymphoma kinase; EML4-ALK, echinoderm microtubule associated protein like 4-anaplastic lymphoma kinase; Grp94, glucose-regulated protein 94; Grp78, glucoseregulated protein 78; ATF4, anti-activating transcription factor 4; CHOP, nuclear transcription factor.

including RAF, ErbB2, EGFR, MAK and hTERT, have been found to interact with Hsp90 and play important roles in the development of lung cancer $(44,45)$.

\section{Expression of Hsp90 in lung cancer}

Table I lists the recent important findings on the expression of Hsp90 in lung cancer. Hsp90 is highly expressed in NSCLC patients, and increased Hsp90 positively correlates with age, lung squamous cell carcinoma (LSCC), ever-smoking history and metastasis of lymph node (46). Also, overexpression of Hsp90 in NSCLC patients relates with shorter overall survival (47), suggesting that it could be used to predict survival (48). In parental T2821 and T2851 cells of lung cancer, the protein expression of Hsp90 is upregulated, and in radioresistant T2821/R and T2851/R cells lines this phenomena is eminent and intimately correlates with the radioresistance of T2821/R and T2851/R cells (49). Compared with the control cells, the expression of Hsp90 in SPCA-1 and H446 cell lines of lung cancer is upregulated remarkably, which presents a dose-dependent pattern to geranylgeranylacetone (50). High expression of Hsp90 is also associated with male patients, patients with smoking index over 600 , and SCLC (51). One study reports that overall survival (OS) of high-Hsp90 $\beta$ expression lung cancer is shorter than that of low-Hsp90 $\beta$ group and Hsp90 $\beta$ is an independent prognostic factor (11). In addition, overexpression of Hsp90 $\beta$ is found in tissues of lung adenocarcinoma, which is related to the poorly differentiated grade, shorten OS (52) and lymphatic invasion (10). Increased serum Hsp90 $\beta$ correlates with the differentiated grade and advanced clinical stage of patients with lung cancer, and assists the diagnosis and prognosis estimation (13). In one comparative study, Hsp90 $\beta$ in lung cancer tissues showed a higher expression than that in normal lung tissue and $\mathrm{Hsp} 90 \beta$ presents a higher expression in LAC tissues than in LSCC, and correlates with the poor survival of LAC patients (53). A study with a total of 2,247 individuals demonstrates that the plasma Hsp90 $\alpha$ of lung cancer patients has a significantly higher level and correlates with advanced stage of lung cancer patients (stage III-IV) (54).

Currently, there are still some limitations on investigating the expression of Hsp90 in lung cancer. First, we still lack large number of samples and multiple center research. There is no high quality research concerning the expression of Hsp90 in lung tissues, blood, BALF, and malignant pleural effussion (MPE). Second, previous studies do not focus on Hsp90 gene 


\section{Hsp90 inhibitors}

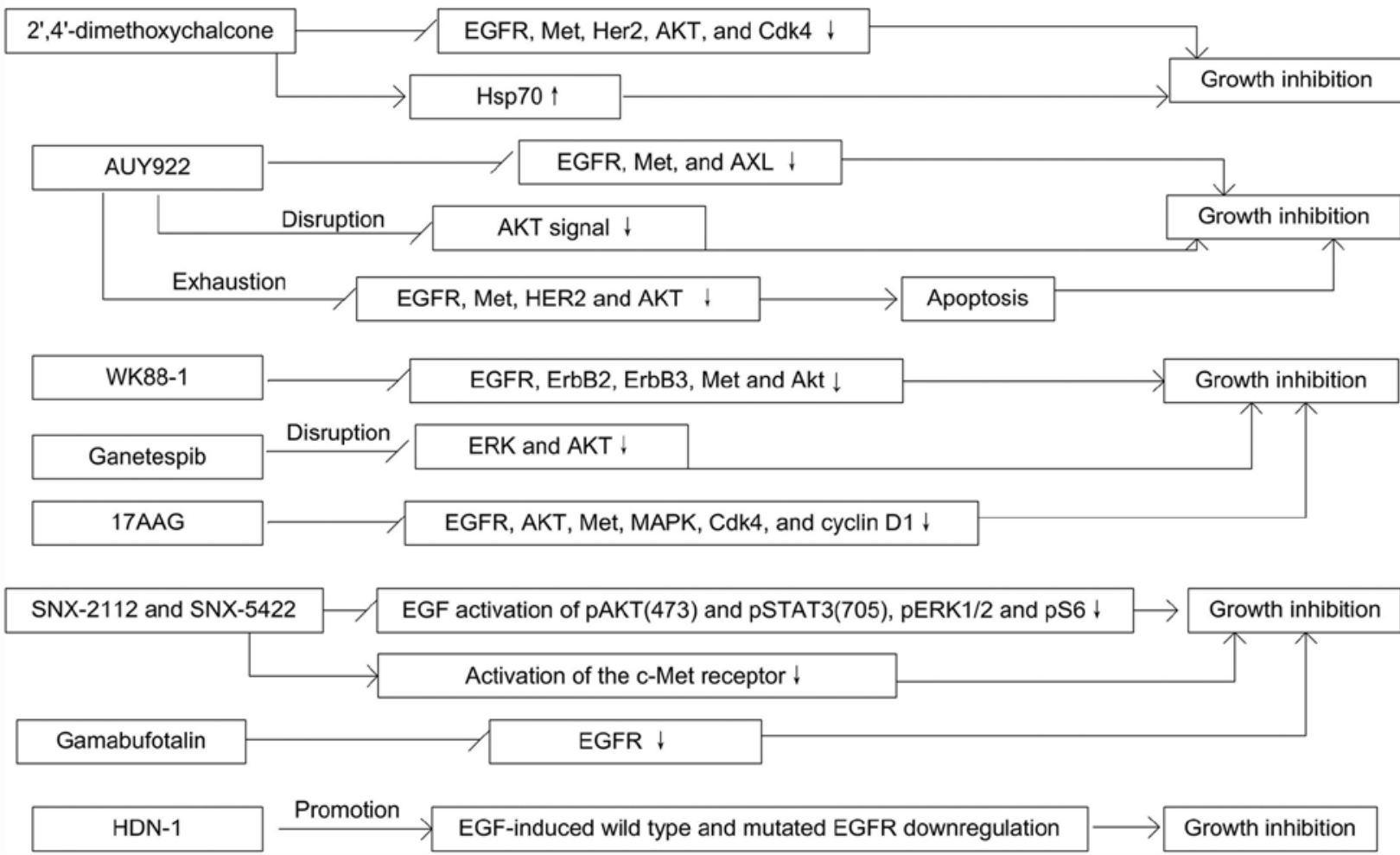

Figure 4. Influence of Hsp90 on the growth of lung cancer via EGFR signaling pathways. Hsp90 inhibition decreases the growth of NSCLC cells by downregulating EGFR, Met, Her2, Akt, and Cdk4, and upregulating Hsp70, and inhibits the proliferation and induces cell death by downregulation of EGFR and AXL. Hsp90 inhibition results in exhaustion of EGFR, Met, HER2 and AKT, which leads to the reinforcement of apoptosis; Hsp90 inhibition reduces the lung cancer cell survival via reducing the expression of EGFR, ErbB2, ErbB3, Met and Akt. Hsp90 inhibition and erlotinib stabilizes the expression state of EGFR inactivation and disrupts ERK and AKT signaling activity, which is associated with downregulation of EGFR and Met. Inhibition of Hsp90 exhausts EGFR, AKT, MAPK, Cdk4, and cyclin D1 and suppresses EGF activation of pAKT(473) and pSTAT3(705), pERK1/2 and pS6 and causes c-Met degradation; suppression of Hsp90 reduces expression of Hsp90-dependent client protein EGFR and results in a potential conformational change and degrades multiple oncoproteins and promotes EGF-induced wild-type and mutated EGFR downregulation. Hsp90, heat shock protein 90; EGFR, epidermal growth factor receptor; CDK4, cyclin-dependent kinase 4; ERBB, human epidermal growth factor receptor; AKT, anaplastic lymphoma kinase; Met, Met gene; Her2, human epidermal growth factor receptor-2; AXL, receptor tyrosine kinase; ERK, extracellular-signal-regulated kinase; MAPK, mitogen-activated protein kinase; EGF, epidermal growth factor; STAT3, signal transducer and activator of transcription 3; c-Met, proto-oncogene.

mutations and abnormal copy. Because a great deal of studies on inhibitors of Hsp90 that fight against lung cancer show that not all lung cancer respond with definite efficacy to inhibitors of Hsp90.

\section{Biological functions of Hsp90 in lung cancer}

From 2000 to now, investigating the relation between Hsp90 and lung cancer has become a very active field, especially on the efficacy of Hsp90 inhibitors that fight against lung cancer. It seems that different $\mathrm{Hsp} 90$ inhibitors affect different signaling pathways via specific signal molecules in development of lung cancer.

Influence of Hsp90 on cell cycle regulation and cell apoptosis of lung cancer. As shown in Fig. 3, Hsp90 inhibitor FS-108 induces $\mathrm{G} 2 / \mathrm{M}$ phase arrest of gefitinib-resistant lung cancer cells by reducing the expression of $\mathrm{Cdc} 2$ and $\mathrm{Cdc} 25 \mathrm{C}$, and promotes apoptosis of gefitinib-resistant cells via a caspasedependent pathway (55). STA-8666 combines a chemical moiety targeting active Hsp90 fused via cleavable linker to the active metabolite of irinotecan (SN38), and induces cell cycle arrest, associating with DNA damage and cell cycle checkpoints, and apoptosis (56). Hsp90 inhibitor 17-AAG arrests cell cycles of lung cancer A549 and H446 cells at the G2/M phase and promotes apoptosis via regulating the expression of apoptosis-related proteins (Bax and Bcl-2) (57), and combination of 17-AAG and carbon ions shows treatment efficacy in lung cancer, which results in a definite $\mathrm{G} 2$ cell cycle delay (58). Geldanamycin and 17-AAG inhibit the growth of lung cancer cell lines via inducing G2/M arrest concomitant with decreased protein levels of $\mathrm{Cdc} 25 \mathrm{C}$ and $\mathrm{Cdc} 2$ (51). CDBT exerts an antitumor activity in P-gp overexpressing drugresistant NSCLC H460TaxR cells by the destabilization of microtubules, degradation of CRAF-1 and ErbB2 and phosphorylated AKT (44), leading to cell cycle arrest at the G2/M phase and reinforcement of apoptosis (59). Hsp90 inhibition of IPI-504 results in disruption of EML4-ALK and inhibition of its downstream signaling pathways, which induces growth arrest and apoptosis in cells carrying the EML4-ALK fusion (60). Hsp90 inhibitor PU-H71 upregulates Grp94, Grp78, ATF4 and CHOP, inducing apoptosis of lung cancer cells by downregulation of $\mathrm{Bcl}-2$, upregulation of Bax, release of cytochrome $c$ and activation of caspases (61). 
Hsp90 regulates the growth of lung cancer via EGFR-related signaling pathways. As shown in Fig. 4, Hsp90 inhibitor, 2',4'-dimethoxychalcone (1b) suppresses the growth of Iressaresistant NSCLC H1975 cells by downregulating EGFR, Met, Her2, AKT, and Cdk4, and upregulating Hsp70 (62). Hsp90 inhibitor AUY922 inhibits the proliferation of lung cancer cells and induces cell death by downregulation of EGFR, Met, and AXL, leading to disruption of AKT signal (63). Furthermore, AUY922 results in obvious exhaustion of EGFR, Met, HER2 and AKT in NSCLC cell lines, giving rise to a reinforcement of apoptosis (64). Hsp90 inhibitor WK88-1 reduces the cell survival of lung cancer cells via reducing the expression of EGFR, ErbB2, ErbB3, Met and Akt (65), and combination treatment of Hsp90 inhibitor ganetespib and erlotinib stabilizes the expression state of EGFR inactivation and disrupts ERK and AKT signaling activity (66). Hsp90 inhibitor 17-DMAG inhibits the growth of Ma-1/HGF cells, H1975 cells and PC-9 cells by downregulating EGFR and Met (67) and exhausting EGFR, AKT, MAPK, Cdk4, and cyclin D1 in EGFR-mutant cell lines (68). Hsp90 inhibitors SNX-2112 and SNX-5422 alone and in combination with erlotinib suppresses EGF activation of pAKT(473) and pSTAT3(705), pERK1/2 and pS6 and decreases EGF cross-talk and activation of the c-Met receptor (69). Gamabufotalin inhibits the chaperone function of Hsp90 by reducing expression of Hsp90-dependent client protein EGFR (45). Hsp90 inhibitor HDN-1 binds to C-terminus of Hsp90 $\alpha$ and degrades multiple oncoproteins, promoting EGF-induced wild-type and mutated EGFR downregulation $(70)$.

Hsp90 regulates the growth of lung cancer via $R A S-R A F$ MEK-ERK-MAPK, PI3K/AKT, TGF and VEGF signaling pathways. As shown in Fig. 5, Hsp90 inhibitor AUY922 inhibits the signals of PI3K-AKT-mTOR and RAF-MEK-ERK and exerts antitumor activity (71). 17-DMAG reduces the survival of SCLC cell lines via downregulating protooncogene c-RAF (72) and also reduces XRCC1 expression via inactivation of ERK $1 / 2$ and $\mathrm{AKT}$ enhancing antitumor activity of gefitinib (73). Defects or polymorphisms of MSH2 correlates with lung cancer, 17-AAG leads to enhanced cytotoxic effect accompanied by the reduction of MSH2 via downregulation of the MKK3/6-p38 MAPK signal and inactivation of p38 MAPK (74). In addition, 17-AAG leads to a decrease of cellular thymidine phosphorylase via ubiquitin-26S proteasome pathway with downregulation of phosphorylated MKK1/2-ERK1/2 and AKT protein levels (75). Hsp90 inhibitor CUDC-305 leads to the degradation of RTKs, and disrupts the signaling molecules of the PI3K/AKT and RAF/MEK/ERK pathways, with concurrent induction of apoptosis (76). Hsp90 inhibitor deguelin reveals an anti-Hsp90 activity and keeps a lid on the expression of a number of client proteins of Hsp90, which is involved in the PI3K/AKT pathway (77). Inhibition of Hsp90 by CS-6 prohibits lung cancer growth by targeting IKK $\beta / N F-\kappa B$, which reduces the expressions of hTERT, HIF-1 $\alpha$, VEGF, CDK4, HER2, p-Akt, cyclin D1, p110 $\alpha$ and p-p85 (45). Hsp90 inhibitor L80 disrupts the correlation of HIF-1 $\alpha$ and Hsp90 by reducing HIF-1 $\alpha$, VEGF and IGF2 (78). Hsp90 inhibition by CH5164840 with erlotinib treatment abolishes phosphorylation of Stat 3 in lung cancer cells, which downregulates ERK signaling (79). Repair protein Rad51 protects NSCLC cells against chemotherapeutic cytotoxicity, but Hsp90 inhibitor 17-AAG cuts down the levels of Rad51 and decreases the phosphorylation of MKK1/2-ERK1/2 (80). Furthermore, Hsp90 inhibition caused by ganetespib shows an obvious cell killing in lung cancer cells, with concomitant destabilization of KRAS signaling effectors, and combination of ganetespib and MEK or PI3K/mTOR inhibitors leads to a remarkable cytotoxic activity (81).

Some new molecular signals involved in network of Hsp90 in lung cancer. As shown in Fig. 6, Hsp90 inhibitor 17-AAG downregulates the expression of $\mathrm{MSH} 2$ in human lung cancer and its combination with tamoxifen reinforces cytotoxicity and cell growth inhibition synergistically via reducing $\mathrm{MSH} 2$ expression (82). As a potent proteasome inhibitor, PS-341 inhibits various types of cancer, interestingly, Hsp90 inhibitor 17-AAG enhances PS-341-induced lung cancer cell death by degrading upstream regulators of I $\kappa$, IRAK-1, and I $\mathrm{B}$ kinases (IKKs) (83). In addition, combination of 17-DMAG and TNF brings about synergistic killing of lung cancer cells via downregulation of IKK $\beta$ (84). Hsp90 inhibitor ganetespib induces loss of EML4-ALK expression and depletion of multiple oncogenic signaling proteins in ALK-driven NSCLC cells (85). Inhibition of Hsp90 by NVP-AUY922 suppresses the growth of NSCLC cells, which involves a wide range of cellular functions via consistently decreasing the levels of dihydrofolate reductase (86). Cellular FLICE-inhibitory protein (long form, c-FLIPL) is a critical negative regulator of death receptor-mediated apoptosis, however, depletion of Hsp90 $\alpha / \beta$ decreases c-FLIPL level, and combination of 17-AAG and celecoxib reinforces this results by caspase activation (87). Ganetespib blocks Hsp90 to bind to biotinylated geldanamycin and disintegrates the relation of Hsp90 with its co-chaperone, p23, which inhibits the growth of lung cancer (88). Hsp90 inhibitor deguelin binds to the ATP-binding pocket of Hsp90 and disrupts Hsp90 function by ubiquitin-mediated degradation of HIF-1 $\alpha$ (89). Moreover, combination of 17-AAG and TNF induces apoptosis-related cell death of lung cancer cells by degrading RIP and IKK $\beta$ that, in turn, blocks TNF-induced $\mathrm{NF}-\kappa \mathrm{B}$ activation (90).

\section{Hsp90-dependent radiosensitization in treatment of lung cancer}

The combined treatment of Hsp90 inhibitors and conventional photon radiation has shown more effective tumor growth inhibition than radiation alone, and a number of Hsp90 inhibitors are also known to sensitize cancer cells to radiation. Hsp90 inhibitor ganetespib sensitizes NSCLC cells to radiation (91) via potentiating the effect of radiotherapy and eliminating radioresistant residual cells (49). A purinescaffold Hsp90 inhibitor, PU-H71, promotes the sensitivity of the lung cancer cells to radiation by inhibiting the repair of DSBs (92). 17-AAG and 17DMAG (Hsp90 inhibitors) have been reported to be potent radio-sensitisers, achieving radiation enhancement ratios ranging from 2.3 to 2.7 (93). Co-treatment of 17-DMAG with radiation has a synergistic antitumor activity in NSCLC cells, which involves in inhibition of DNA repair and correlates with the BER and ATM-regulated pathways (94). Combination of irradiation 

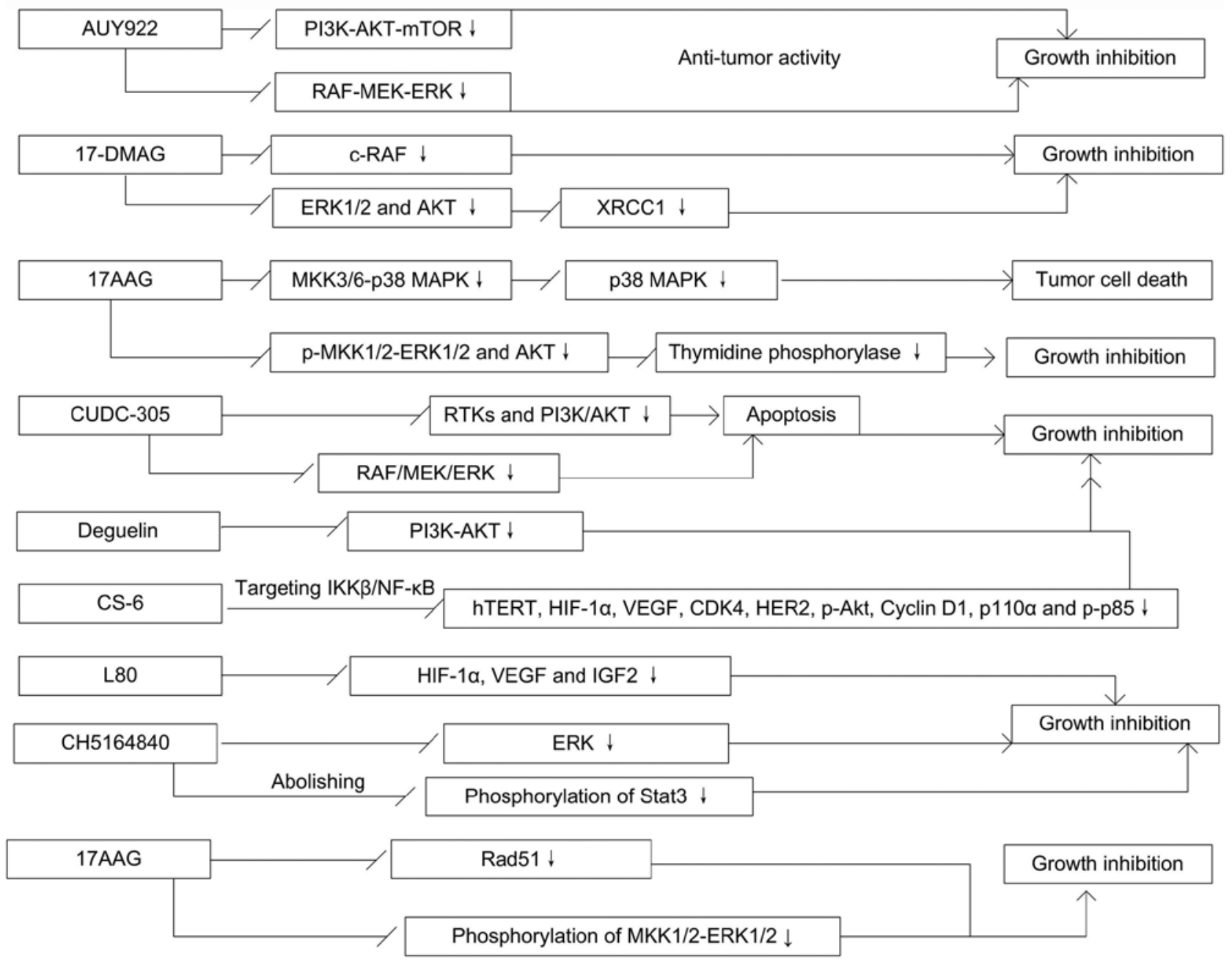

Ganetespib KRAS signaling $\downarrow$

Growth inhibition

Figure 5. Hsp90 regulates the growth of lung cancer via RAS-RAF-MEK-ERK-MAPK, PI3K/AKT, TGF and VEGF signaling pathways. Hsp90 inhibition inhibits the signals of PI3K-AKT-mTOR and RAF-MEK-ERK and thus impedes the growth and proliferation of NSCLC cells. Inhibition of Hsp90 reduces the survival ability of SCLC cells via downregulating expression of proto-oncogene c-RAF and inactivation of ERK1/2 and AKT as well as the reduction of XRCC1. Hsp90 inhibition leads to cytotoxic effect to NSCLC cells and accompanies with the reduction of MSH2 via downregulation of the MKK3/6-p38 MAPK signal and inactivation of p38 MAPK and leads to downregulation of cellular TP via a ubiquitin-26S proteasome pathway, which is accompanied by a downregulation of phosphorylated MKK1/2-ERK1/2 and AKT protein levels. Hsp90 inhibition give rise to degradation of RTKs, and disrupts the signaling molecules of the $\mathrm{PI} 3 \mathrm{~K} / \mathrm{AKT}$ and RAF/MEK/ERK pathways. Inhibition of Hsp90 targets IKK $\beta / \mathrm{NF}-\mathrm{\kappa B}$ to prohibit lung cancer growth, and reduces the expressions of hTERT, HIF-1 $\alpha$, VEGF, CDK4, HER2, p-Akt, cyclin D1, p110 $\alpha$ and p-p85. Disruption of Hsp90 function leads to the disruption of correlation between HIF-1 $\alpha$ and Hsp90 by reducing HIF-1 $\alpha$, VEGF and IGF2. Hsp90 inhibition abolishes phosphorylation of Stat3 and give rise to downregulation of ERK signaling. Hsp90 inhibition cuts down the levels of Rad51, phosphorylated MKK1/2-ERK1/2 and damages the correlation of Hsp90 and Rad51 and leads to a remarkable cytotoxic activity via destabilization of KRAS signaling. Hsp90, heat shock protein 90; PI3K, phosphatidylinositol-4,5-bisphosphate 3-kinase; AKT, anaplastic lymphoma kinase; mTOR, mammalian target of rapamycin; RAF, rapidly accelerated fibrosarcoma gene; MEK, mitogen-activated protein kinase; ERK, extracellularsignal-regulated kinase; c-RAF, threonine protein kinase; XRCC1, X-ray repair cross-complement group 1 protein; MKK3, a dual-specificity protein kinase of the STE7 family; MAPK, mitogen-activated protein kinase; TP, thymidine phosphorylase; RTKs, receptor tyrosine kinases; IKK $\beta$, inhibitor of nuclear factor $\kappa B$ kinase; NF- $\mathrm{BB}$, nuclear factor $\mathrm{\kappa B}$; hTERT, human telomerase reverse transcriptase; HIF-1 $\alpha$, hypoxia-inducible factor-1; VEGF, vascular endothelial growth factor; HER2, human epidermal growth factor receptor-2; p110 $\alpha$, enhanced phosphoinositide 3-kinase; IGF2, insulin-like growth factor 2; Rad51, DNA double strand break repair gene.

and 17-AAG displays an additive effect on cell growth inhibition by downregulating the expressions of Cdc25C and Cdc2 (51). Hsp90 inhibitor NVP-AUY922 results in radiosensitization, which is accompanied by DNA repair effect, cell cycle progression and abrogation of homologous recombination (95). Co-treatment of NVP-AUY922 and 17-AAG leads to upregulation of HIF-1 $\alpha$ and thus shows a promotion of radiosensitivity (96). Especially, celastrol disrupts the ATP-binding activity of Hsp90, and thus reinforces the radiation-induced cell killing by decreasing levels of EGFR, ErbB2 and survivin and increasing p53 expression (97). Hsp90 inhibitor deguelin suppresses radioresistant lung cancer cells and combined treatment of radiation with deguelin cuts down the viability and vascularization of 
Hsp90 inhibitors

Mechanism

Results

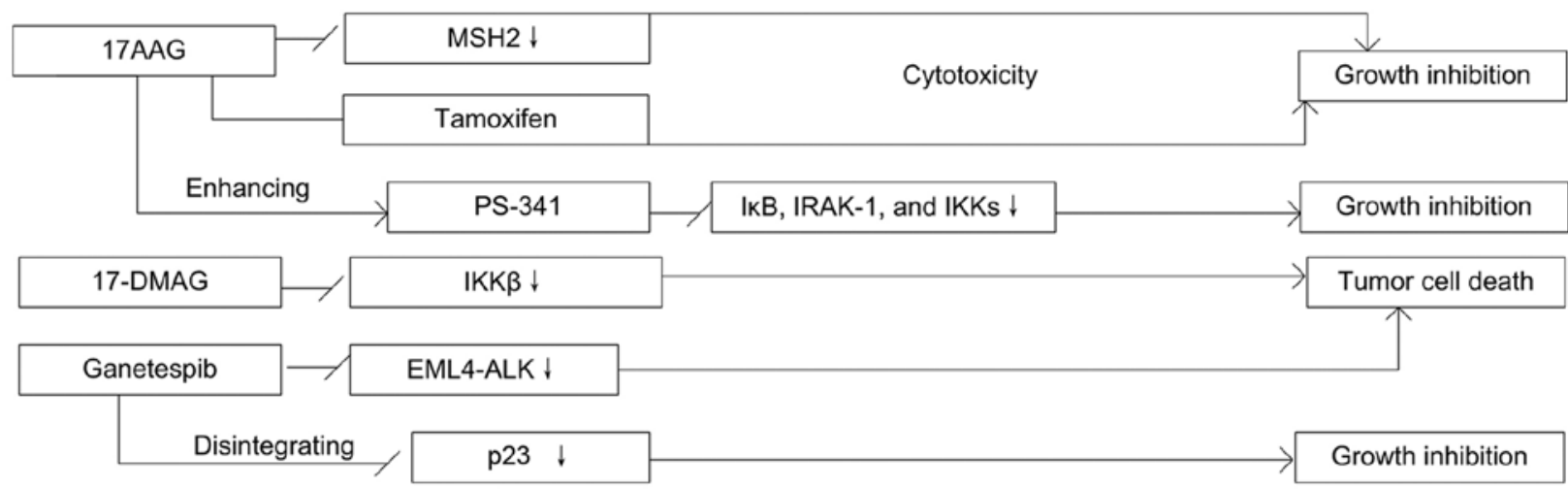

NVP-AUY922

Figure 6. New signaling pathways of inhibition of Hsp90 for regulating the growth of lung cancer. Hsp90 inhibition downregulates the expression of MSH2 and tamoxifen combined with Hsp90 inhibition give rise to cytotoxicity and cell growth inhibition synergistically in NSCLC cells via reducing MSH2 expression. Hsp90 inhibition enhances PS-341-induced lung cancer cell death by degrading IkB, IRAK-1 and IKKs. Combination treatments of Hsp90 inhibition and TNF brings about synergistic killing of lung cancer cells via downregulation of IKK $\beta$. Hsp90 inhibition induces loss of EML4-ALK expression and depletion of multiple oncogenic signaling proteins in ALK-driven NSCLC cells. Hsp90 inhibition disintegrates the relation of Hsp90 with p23 and depletion of Hsp90 $/$ / decreases c-FLIPL level and combination of Hsp90 inhibition and celecoxib reinforces this effect by caspase activation, and leads to ubiquitin-mediated degradation of HIF-1 $\alpha$. Combination of Hsp90 inhibition and TNF induces apoptosis-related cell death of lung cancer cells by degradation of RIP and IKK $\beta$ and blocking of TNF-induced NF-кB activation. Hsp90, heat shock protein 90; MSH2, human MutS homolog 2; PS-341, a potent proteasome inhibitor;

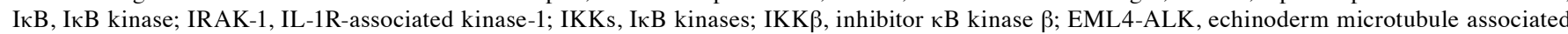
protein like 4-anaplastic lymphoma kinase; ALK, anaplastic lymphoma kinase; c-FLIPL, cellular FLICE-inhibitory protein; p23, important co-chaperone for the Hsp90; HIF-1 $\alpha$, hypoxia-inducible factor-1; RIP, receptor-interaction proteins.

radioresistant cells by blocking the HIF-1 $\alpha / \mathrm{Hsp} 90$ interaction and HIF-1 $\alpha$ expression (98).

\section{Hsp90 and drug resistance of lung cancer}

Hsp90 and drug resistance of traditional chemotherapy. As shown in Table II, upregulated Hsp90 has been investigated in connection with the chemoresistance to cisplatin in LAC cells (50), however, inhibition of Hsp90 increases the sensitivity of cells to cisplatin by inducing AMH and AMHR2 expression (99). Hsp90 inhibitor 17-AAG increases the cisplatin-induced cell-killing via suppressing TP expression and activation of ERK1/2 and AKT (75). Hsp90 inhibitor L80 suppresses the proliferation, survival, and migration of lung cancer cells acquired resistance to paclitaxel (78). Hsp90 inhibitor ganetespib facilitates the cell-killing activity of paclitaxel and docetaxel in NSCLC models (100) and 17-AAG reinforces the cytotoxic effect of etoposide by inhibiting the expression of ERCC1 (101). Also, Hsp90 inhibitor STA-8666 combines a chemical moiety targeting active Hsp90 fused via cleavable linker to active metabolite of irinotecan SN38, thus strongly promotes the antitumor activity of carboplatin (56).
Hsp90 and drug resistance of molecular targeted therapy. As shown in Table II, some Hsp90 inhibitors show activity of reversing molecular targeting drug resistance and synergism. FS-108 circumvents gefitinib resistance in EGFR mutant NSCLC cells through inducing G2/M phase arrest and apoptosis (55). AUY922 inhibits growth of EGFR-TKI resistant cell lines by inducing cell programmed death (63) and also displays activity against the gefitinib-resistant sublines with T790M mutation and Met amplification (102). WK88-1 reverses gefitinib resistance by interfering the EGFR or c-Met stability and functions (65). 17-AAG represents a better efficacy for treating NSCLC with acquired resistance to EGFR TKIs (103) and the combination of gefitinib and 17-AAG increases NSCLC cell growth inhibition (73). SH-1242 targets those cells that are chemoresistant or harbor KRAS mutations (104) and exerts cytotoxicity to lung cancer cells. Pyruvate kinase M2 (PKM2) interacts with mutant EGFR and Hsp90 contributing to EGFR-dependent tumorigenesis and facilitates to overcome drug resistance to EGFR TKIs (105). 2',4'-dimethoxychalcone (1b) restrains the proliferation of iressa-resistant NSCLC cells by circumventing the drug-resistance acquired by Met amplification and EGFR mutations (62). Ganetespib shows a 


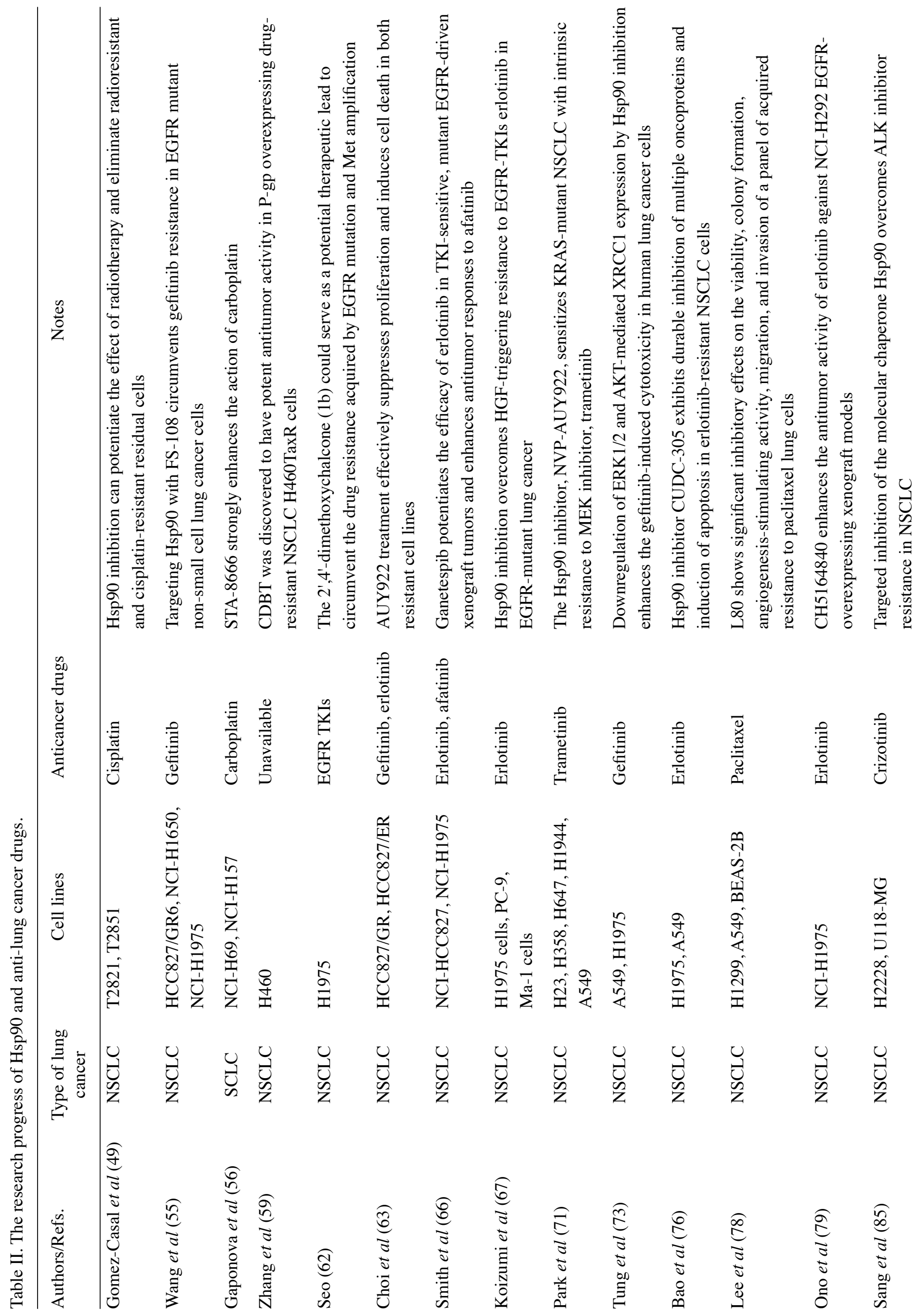




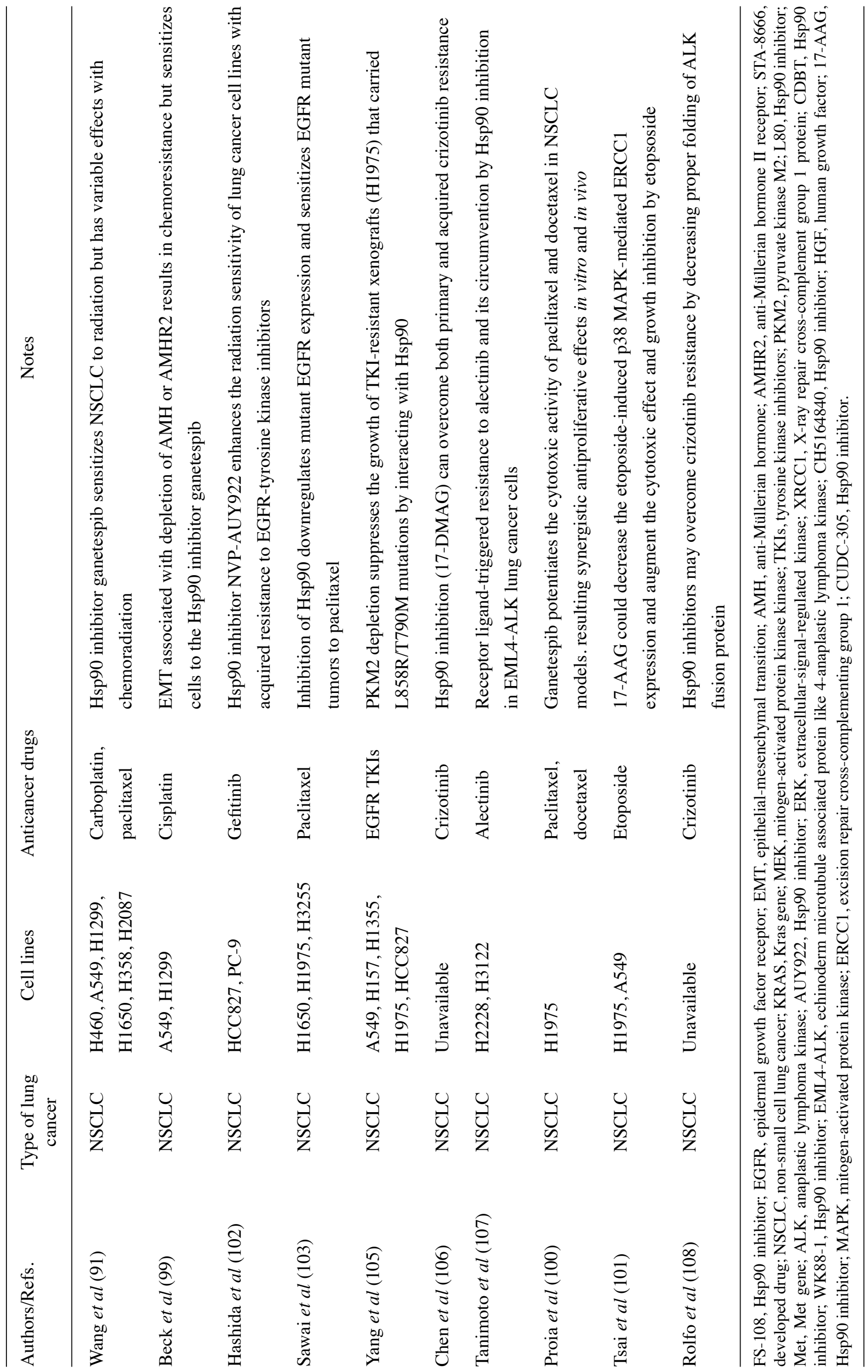


remarkable ability to defeat multiple forms of crizotinib resistance, including secondary ALK mutations (85). 17-DMAG can circumvent both primary and acquired crizotinib resistance (106). Ganetespib promotes the antitumor activity of erlotinib in erlotinib-resistant NCI-H1975 xenografts and also increases efficacy of afatinib (66). CH5164840 can increase the anticancer activity of erlotinib against NCI-H292 EGFR-overexpressing xenograft models (79). CUDC-305 induces apoptosis and inhibits cancer growth of erlotinibresistant NSCLC cells (76). CDBT has been discovered to have a potent activity against $\mathrm{P}$-gp overexpressing drug-resistant NSCLC H460TaxR cells (59). Hsp90 inhibitors also overcome ligand-triggered resistance to new generation ALK inhibitors and may bring improved benefit for NSCLC patients with EML4-ALK $(107,108)$.

\section{Clinical research on Hsp90 inhibitors for treating lung cancer}

The potential anticancer activity of some Hsp90 inhibitors for treating lung cancer has been proven in preclinical in vitro and in vivo models. For instance, recently a clinical trial evaluated the activity and safety of Hsp90 inhibitor ganetespib in combination with docetaxel in advanced NSCLC, which showed that combination of ganetespib significantly prolongs the PFS and OS and the combination treatment of ganetespib and docetaxel does not have obvious additional side effects (109). NSCLC patients in a previous study were divided into three groups: cohort A (EGFR mutants), B (KRAS mutants), or C (with out mutations of both). Patients of the three groups were all administered ganetespib of $200 \mathrm{mg} / \mathrm{m}^{2}$ via intravenous infusion (1/week; rest for a week after 3 weeks), until disease progression. The results showed that ganetespib monotherapy presents a manageable side effect profile as well as clinical activity in heavily pretreated patients with advanced NSCLCs, particularly in patients with tumors harboring ALK gene rearrangement (110). Another prospective, non-randomized, multicenter, phase II study of IPI-504 monotherapy has shown that IPI-504 has certain clinical activity in patients with NSCLC, particularly among patients with ALK rearrangements (111). However, the clinical research on the Hsp90 inhibitor for treating lung cancer is only at the beginning, it seems that these studies did not produce an impressive breakthrough as we expected. Because Hsp90 conduces to the maturation and stability many mutated or overexpressed oncogenic proteins, targeting Hsp90 has been considered as an effective anticancer therapy. Although the WCLC2016, GALAXY-2 study showed that the addition of ganetespib as a rescue treatment on the basis of docetaxel did not improve efficacy. The combination application of Hsp90 inhibitors and other traditional chemotherapy is still greatly worthy of further exploration. However, the clinical research of Hsp90-dependent molecular targeted therapy (Hsp90 inhibitors) is an area where we have really fallen far behind. We must acknowledge that the main reason of leading to the embarrassing situation correlates with medical ethics and strict approval system of new drugs in all countries; after all, we are faced with humans. However, clinical research and application is the only way and the ultimate goal. Only this way, can we bring benefits to lung cancer patients from Hsp90 inhibitors.

\section{Perspective and limitation}

The clinical benefit of current anticancer regimens for lung cancer therapy is still limited due to moderate efficacy, drug resistance, and early recurrence. Therefore, the development of effective new anticancer drugs for first-line therapy and for optimal second-line treatment is necessary. Study on the molecular mechanism of Hsp90 in lung cancer has made some progress as well as greatly promoting the development of Hsp90-dependent molecular targeted drugs. However, there are some shortcomings in current research. So far, no large sample numbers and multiple centers on the expression of Hsp90 in lung cancer are reported, including in lung tissues, blood, bronchoalveolar lavage fluid and malignant pleural effussion. In addition, no studies keep a watchful eye on gene mutations and copy abnormality of Hsp90, which may be correlated with the efficacy of Hsp90 inhibitors such as EGFR mutations. Importantly, although clinical studies to evaluate the activity and safety of $\mathrm{Hsp} 90$ inhibitors in treating lung cancer patients has been reported occasionally, it seems that quality and scale of these studies could not support the evidence of clinical application of Hsp90 inhibitors. To assess whether Hsp90 inhibitor proves to be a successful therapeutic strategy in treating lung cancer patients, we still need to do further research, such as construction of drug delivery vehicles, design of clinical research and evaluation of side effects. Future research should focus on assessing the activity and safety of Hsp90 inhibitors in clinical lung cancer patients and establish the most effective Hsp90 inhibitors for treating lung cancer.

\section{Conclusion}

Research shows that Hsp90 is highly expressed in lung cancer and that upregulation of Hsp90 potentially facilitates proliferation and metastasis of lung cancer. However, anti-Hsp90 (Hsp90 inhibitors) studies have demonstrated that downregulation and function disruption of Hsp90 inhibits cell proliferation, motility and metastasis, and induces apoptosis of lung cancer cells. However, there is an urgent need for a comprehensive assessment of $\mathrm{Hsp} 90$ protein expression and gene abnormality in large cohorts of lung cancer. In addition, high quality clinical research on Hsp90 inhibitors are also needed for evaluating the efficacy and safety in clinical recommendation. Actually, we still know relatively little as to how the Hsp90 regulates tumorigenesis of lung cancer at the molecular level, thus improved understanding of the molecular mechanisms and signaling pathways correlated with Hsp90 present an interesting challenge, and a future important direction.

\section{Acknowledgements}

This study was supported by grants from the Scientific Research Plan projects of Shaanxi Province Education Department (No. 17JK0661).

\section{Abbreviations}

17-AAG, Hsp90 inhibitor; 17-DMAG, 17-demethoxygeldanamycin; Hsp90 inhibitor; Abl, Src family tyrosine kinase; Aha1, 
activator of Hsp90 ATPase; AKT, anaplastic lymphoma kinase; ALK3, AMHR2 heterodimerizes with type I receptors; AMH, anti-Müllerian hormone; AMHR2, anti-Müllerian hormone type II receptor; APC/C, anaphase promoting complex; ATF4, anti-activating transcription factor 4; AT13387, Hsp90 inhibitor; ATM, ataxia-telangiectasia mutant; ATP, adenosinetriphosphate; ATPase, adenosinetriphosphatease; AUY922, Hsp90 inhibitor; AXL, receptor tyrosine kinase; BAD, Bcl-2associated death promoter; BALF, bronchoalveolar lavage fluid; Bcl-2, B-cell lymphoma-2; Bax, bcl-2-like protein 4; $\mathrm{BER}$, base excision repair; BMP, bone morphogenetic protein; Cdc2, cell division cycle 2; CDBT, Hsp90 inhibitor; Cdc25C, cell division cycle 25C; $\mathrm{Cdc} 37$, cell division cycle 37; Cdk, cyclin-dependent kinase; c-FLIPL, cellular FLICE-inhibitory protein; CHOP, nuclear transcription factor; CH5164840, Hsp90 inhibitor; CK2, casein kinase 2; COX-2, cyclooxygenase-2; CRAF-1, threonine protein kinase; CS-6, Hsp90 inhibitor; Cyp40, cyclophilin 40; CUDC-305, Hsp90 inhibitor; DSBs, DNA double-strand breaks; EGF, epidermal growth factor; EGFR, epidermal growth factor receptor; EML4-ALK, echinoderm microtubule associated protein like 4-anaplastic lymphoma kinase; EMT, epithelial-mesenchymal transition; ER, estrogen receptor; ErbB2/HER2, human epidermal growth factor receptor-2; ERBB2 YVMA, a 12-bp duplication/insertion of the amino acid sequence YVMA in exon 20 at codon 776; ERCC 1, excision repair cross-complementary 1; ERK, extracellular-signal-regulated kinase; FAK, focal adhesion kinase; Fes, Src family tyrosine kinase; Fkbp51, Hsp90-associated human peptidyl prolyl cis/trans isomerases; Fkbp52, Hsp90-associated human peptidyl prolyl cis/trans isomerases; Fps, Src family tyrosine kinase; FS-108, Hsp90 inhibitor; Gp96, a receptor for heat shock protein 90; Grp94, glucose-regulated protein 94; Grp78, glucose-regulated protein 78; HDAC6, histone deacetylase 6; HDACi, histone deacetylase inhibitor; HDN-1, Hsp90 inhibitor; HEY-1, hairy/ enhancer-of-split related with YRPW motif protein 1; Her2, human epidermal growth factor receptor-2; HES-1, Hes family BHLH transcription factor 1; HGF, hepatocyte growth factor; HIF-1 $\alpha$, hypoxia-inducible factor-1; Hop/Sti1, hop-like stressinduced protein 1 co-chaperone; Hsp90, heat shock protein 90 ; hTERT, human telomerase reverse transcriptase; IGF-I, insulinlike growth factor 1; IGF2, insulin-like growth factor 2; IкB, I $\kappa \mathrm{B}$ kinases; IKK $\beta$, inhibitor of nuclear factor $\kappa \mathrm{B}$ kinase; IKKs, inhibit $\kappa \mathrm{B}$ kinase complex; IPAK-1, Toll-like receptor-associated kinases; IPI-504, Hsp90 inhibitor; IL-1R, interleukin-1 receptor; IRAK-1, IL-1R-associated kinase-1; kDa, atomic mass unit; Lck, Src family tyrosine kinase; LAC, lung adenocarcinoma; L80, Hsp90 inhibitor; L858R, leucine substitution at amino acid 858; LPLTPLP, Hsp90 inhibitor; MAPK, mitogen-activated protein kinase; MEK, mitogenactivated protein kinase/extracellular signal-regulated kinase kinase; Met, Met gene; MKK, a dual-specificity protein kinase of the STE7 family; MMP, matrix metalloproteinase; MPE, malignant pleural effussion; MSH2, human MutS homolog 2; NF- $\mathrm{B}$, nuclear factor $\kappa \mathrm{B}$; NVP-AUY922, Hsp90 inhibitor; NSCLC, non-small cell lung cancer; OS, overall survival; p1 $10 \alpha$, enhanced phosphoinositide 3-kinase; p23/ Sba1, the protein encoded by the PTGES3 gene; p53, tumor suppressor; p65, transcription factor; P-gp, P-glycoprotein; PKM2, pyruvate kinase M2; PI3K, phosphatidylinositol- 4,5-bisphosphate 3-kinase; Pih1/Nop17, nucleolus homologous protein 17; PP5, protein phosphatase 5; p-p85, phosphorylated p85; PS-341, proteasome inhibitor; pS6, phosphorylated ribosome protein S6; pSTAT3, phosphorylated signal transducer and activator of transcription 3; PTACH, HDAC inhibitor; PU-H71, Hsp90 inhibitor; Rad51, DNA double strand break repair gene; Raf, rapidly accelerated fibrosarcoma gene; RAS, Ras gene; RTKs, receptor tyrosine kinases; RIP, receptorinteraction proteins; SCC, squamous cell carcinoma; SH-1242, analogue of deguelin; SN38, an antineoplastic drug and is the active metabolite of irinotecan; SNX-5422, Hsp90 inhibitor; Src, Src family kinase; STA-8666, Hsp90 inhibitor; STA-1474, Hsp90 inhibitor; T790M, the 790th site of EGFR exon 20; Tah1, TPR7-containing protein associated with Hsp90; TGF, transforming growth factor; TNF, tumor necrosis factor; TP, thymidine phosphorylase; TRAP1, TNF receptor associated protein 1; Unc45b, unc45 myosin chaperone b; VEGF, vascular endothelial growth factor; WK88-1, Hsp90 inhibitor; $\mathrm{XRCC} 1, \mathrm{X}$-ray repair cross-complement group 1 protein; Yes, Src family tyrosine kinase.

\section{References}

1. Biaoxue R, Xiguang C, Hua L and Shuanying Y: Stathmindependent molecular targeting therapy for malignant tumor: The latest 5 years' discoveries and developments. J Transl Med 14: 279, 2016

2. Biao-xue R, Xi-guang C, Shuan-ying Y, Wei L and Zong-juan M: EphA2-dependent molecular targeting therapy for malignant tumors. Curr Cancer Drug Targets 11: 1082-1097, 2011.

3. Biaoxue R, Hua L, Wenlong G and Shuanying Y: Overexpression of stathmin promotes metastasis and growth of malignant solid tumors: A systemic review and meta-analysis. Oncotarget 7: 78994-79007, 2016.

4. Tatokoro M, Koga F, Yoshida S and Kihara K: Heat shock protein 90 targeting therapy: State of the art and future perspective. EXCLI J 14: 48-58, 2015.

5. Chehab M, Caza T, Skotnicki K, Landas S, Bratslavsky G, Mollapour M and Bourboulia D: Targeting Hsp90 in urothelial carcinoma. Oncotarget 6: 8454-8473, 2015.

6. Hall JA, Forsberg LK and Blagg BS: Alternative approaches to Hsp90 modulation for the treatment of cancer. Future Med Chem 6: 1587-1605, 2014.

7. Prodromou C: Mechanisms of Hsp90 regulation. Biochem J 473: 2439-2452, 2016

8. Khurana $\mathrm{N}$ and Bhattacharyya S: Hsp90, the concertmaster: Tuning transcription. Front Oncol 5: 100, 2015.

9. Lianos GD, Alexiou GA, Mangano A, Mangano A, Rausei S Boni L, Dionigi $G$ and Roukos DH: The role of heat shock proteins in cancer. Cancer Lett 360: 114-118, 2015.

10. Biaoxue R, Xiling J, Shuanying Y, Wei Z, Xiguang C, Jinsui W and Min Z: Upregulation of Hsp90-beta and annexin A1 correlates with poor survival and lymphatic metastasis in lung cancer patients. J Exp Clin Cancer Res 31: 70, 2012.

11. Kim SH, Ji JH, Park KT, Lee JH, Kang KW, Park JH, Hwang SW, Lee EH, Cho YJ, Jeong YY, et al: High-level expression of Hsp90 $\beta$ is associated with poor survival in resectable non-small-cell lung cancer patients. Histopathology 67: 509-519, 2015.

12. Miyata Y and Yahara I: The 90-kDa heat shock protein, HSP90, binds and protects casein kinase II from self-aggregation and enhances its kinase activity. J Biol Chem 267: 7042-7047, 1992.

13. Rong B, Zhao C, Liu H, Ming Z, Cai X, Gao W and Yang S: Identification and verification of $\mathrm{Hsp} 90$-beta as a potential serum biomarker for lung cancer. Am J Cancer Res 4: 874-885, 2014.

14. Pillai RN and Ramalingam SS: Heat shock protein 90 inhibitors in non-small-cell lung cancer. Curr Opin Oncol 26: 159-164, 2014.

15. Pennisi R, Ascenzi P and di Masi A: Hsp90: A new player in DNA repair? Biomolecules 5: 2589-2618, 2015.

16. Maloney A and Workman P: HSP90 as a new therapeutic target for cancer therapy: The story unfolds. Expert Opin Biol Ther 2: $3-24,2002$. 
17. Li J and Buchner J: Structure, function and regulation of the hsp90 machinery. Biomed J 36: 106-117, 2013.

18. Verma S, Goyal S, Jamal S, Singh A and Grover A: Hsp90: Friends, clients and natural foes. Biochimie 127: 227-240, 2016.

19. Zhang L, Fok JH and Davies FE: Heat shock proteins in multiple myeloma. Oncotarget 5: 1132-1148, 2014.

20. García R, Merino D, Gómez JM, Nistal JF, Hurlé MA Cortajarena AL and Villar AV: Extracellular heat shock protein 90 binding to TGF $\beta$ receptor I participates in TGF $\beta$ mediated collagen production in myocardial fibroblasts. Cell Signal 28: 1563-1579, 2016

21. Prodromou C, Siligardi G, O'Brien R, Woolfson DN, Regan L, Panaretou B, Ladbury JE, Piper PW and Pearl LH: Regulation of Hsp90 ATPase activity by tetratricopeptide repeat (TPR)-domain co-chaperones. EMBO J 18: 754-762, 1999.

22. Richter K, Muschler P, Hainzl O, Reinstein J and Buchner J: Stil is a non-competitive inhibitor of the Hsp90 ATPase. Binding prevents the $\mathrm{N}$-terminal dimerization reaction during the ATPase cycle. J Biol Chem 278: 10328-10333, 2003.

23. Obermann WM, Sondermann H, Russo AA, Pavletich NP and Hartl FU: In vivo function of Hsp90 is dependent on ATP binding and ATP hydrolysis. J Cell Biol 143: 901-910, 1998.

24. Silverstein AM, Galigniana MD, Chen MS, Owens-Grillo JK, Chinkers $\mathrm{M}$ and Pratt WB: Protein phosphatase 5 is a major component of glucocorticoid receptor.hsp90 complexes with properties of an FK506-binding immunophilin. J Biol Chem 272: 16224-16230, 1997.

25. Wandinger SK, Suhre MH, Wegele H and Buchner J: The phosphatase Ppt1 is a dedicated regulator of the molecular chaperone Hsp90. EMBO J 25: 367-376, 2006.

26. Pirk1F and Buchner J: Functional analysis of the Hsp90-associated human peptidyl prolyl cis/trans isomerases FKBP51, FKBP52 and Cyp40. J Mol Biol 308: 795-806, 2001.

27. Srikakulam R, Liu L and Winkelmann DA: Unc45b forms a cytosolic complex with Hsp90 and targets the unfolded myosin motor domain. PLoS One 3: e2137, 2008.

28. Zhao R, Kakihara Y, Gribun A, Huen J, Yang G, Khanna M, Costanzo M, Brost RL, Boone C, Hughes TR, et al: Molecular chaperone Hsp90 stabilizes Pih1/Nop17 to maintain R2TP complex activity that regulates snoRNA accumulation. J Cell Biol 180: 563-578, 2008.

29. Hessling M, Richter K and Buchner J: Dissection of the ATP-induced conformational cycle of the molecular chaperone Hsp90. Nat Struct Mol Biol 16: 287-293, 2009.

30. Li J, Soroka J and Buchner J: The Hsp90 chaperone machinery: Conformational dynamics and regulation by co-chaperones. Biochim Biophys Acta 1823: 624-635, 2012.

31. Yarden Y and Sliwkowski MX: Untangling the ErbB signalling network. Nat Rev Mol Cell Biol 2: 127-137, 2001.

32. Xu W, Mimnaugh E, Rosser MF, Nicchitta C, Marcu M, Yarden Y and Neckers L: Sensitivity of mature Erbb2 to geldanamycin is conferred by its kinase domain and is mediated by the chaperone protein Hsp90. J Biol Chem 276: 3702-3708, 2001.

33. Schwartzberg PL: The many faces of Src: Multiple functions of a prototypical tyrosine kinase. Oncogene 17: 1463-1468, 1998

34. Perdew GH, Wiegand H, Vanden Heuvel JP, Mitchell C and Singh SSA: A 50 kilodalton protein associated with raf and pp60(v-src) protein kinases is a mammalian homolog of the cell cycle control protein cdc37. Biochemistry 36: 3600-3607, 1997.

35. Dhillon AS, Hagan S, Rath O and Kolch W: MAP kinase signalling pathways in cancer. Oncogene 26: 3279-3290, 2007.

36. Stancato LF, Chow YH, Owens-Grillo JK, Yem AW, Deibel MR Jr, Jove R and Pratt WB: The native v-Raf.hsp90. p50 heterocomplex contains a novel immunophilin of the FK506 binding class. J Biol Chem 269: 22157-22161, 1994.

37. Miyata $Y$ and Yahara I: Interaction between casein kinase II and the 90-kDa stress protein, HSP90. Biochemistry 34: 8123-8129, 1995.

38. Holt SE, Aisner DL, Baur J, Tesmer VM, Dy M, Ouellette M, Trager JB, Morin GB, Toft DO, Shay JW, et al: Functional requirement of p23 and Hsp90 in telomerase complexes. Genes Dev 13: 817-826, 1999.

39. DeZwaan DC, Toogun OA, Echtenkamp FJ and Freeman BC: The Hsp82 molecular chaperone promotes a switch between unextendable and extendable telomere states. Nat Struct Mol Biol 16: 711-716, 2009

40. Sarkar S, Dutta D, Samanta SK, Bhattacharya K, Pal BC, Li J, Datta K, Mandal C and Mandal C: Oxidative inhibition of Hsp90 disrupts the super-chaperone complex and attenuates pancreatic adenocarcinoma in vitro and in vivo. Int J Cancer 132: 695-706, 2013.
41. Song X, Wang X, Zhuo W, Shi H, Feng D, Sun Y, Liang Y, Fu Y, Zhou D and Luo Y: The regulatory mechanism of extracellular Hsp90\{alpha\} on matrix metalloproteinase-2 processing and tumor angiogenesis. J Biol Chem 285: 40039-40049, 2010.

42. Walerych D, Gutkowska M, Klejman MP, Wawrzynow B, Tracz Z, Wiech M, Zylicz M and Zylicz A: ATP binding to Hsp90 is sufficient for effective chaperoning of $\mathrm{p} 53$ protein. $\mathrm{J}$ Biol Chem 285: 32020-32028, 2010.

43. Park SJ, Borin BN, Martinez-Yamout MA and Dyson HJ: The client protein p53 adopts a molten globule-like state in the presence of Hsp90. Nat Struct Mol Biol 18: 537-541, 2011.

44. Zhang Q, Zhai S, Li L, Li X, Zhou H, Liu A, Su G, Mu Q, Du Y and Yan B: Anti-tumor selectivity of a novel tubulin and HSP90 dual-targeting inhibitor in non-small cell lung cancer models. Biochem Pharmacol 86: 351-360, 2013.

45. Zhang L, Yu Z, Wang Y, Wang X, Zhang L, Wang C, Yue Q, Wang X, Deng S, Huo X, et al: Quantitative proteomics reveals molecular mechanism of gamabufotalin and its potential inhibition on Hsp90 in lung cancer. Oncotarget 7: 76551-76564, 2016.

46. Su JM, Hsu YY, Lin P and Chang H: Nuclear accumulation of heat-shock protein 90 is associated with poor survival and metastasis in patients with non-small cell lung cancer. Anticancer Res 36: 2197-2203, 2016

47. Gallegos Ruiz MI, Floor K, Roepman P, Rodriguez JA, Meijer GA, Mooi WJ, Jassem E, Niklinski J, Muley T, van Zandwijk N, et al: Integration of gene dosage and gene expression in non-small cell lung cancer, identification of HSP90 as potential target. PLoS One 3: e0001722, 2008

48. Liu W, Wu Y, Wang L, Gao L, Wang Y, Liu X, Zhang K, Song J, Wang H, Bayer TA, et al: Protein signature for non-small cell lung cancer prognosis. Am J Cancer Res 4: 256-269, 2014.

49. Gomez-Casal R, Epperly MW, Wang H,Proia DA, Greenberger JS and Levina V: Radioresistant human lung adenocarcinoma cells that survived multiple fractions of ionizing radiation are sensitive to HSP90 inhibition. Oncotarget 6: 44306-44322, 2015.

50. Liu T, Wang X and Zhang L: The correlation between the up-regulation of Hsp90 and drug resistance to cisplatin in lung cancer cell line. Zhongguo Fei Ai Za Zhi 14: 472-477, 2011 (In Chinese).

51. Senju M, Sueoka N, Sato A, Iwanaga K, Sakao Y, Tomimitsu S, Tominaga M, Irie K, Hayashi S and Sueoka E: Hsp90 inhibitors cause $\mathrm{G} 2 / \mathrm{M}$ arrest associated with the reduction of $\mathrm{Cdc} 25 \mathrm{C}$ and Cdc2 in lung cancer cell lines. J Cancer Res Clin Oncol 132: $150-158,2006$

52. Wu Y, Huang B, Liu Q and Liu Y: Heat shock protein 90- $\beta$ over-expression is associated with poor survival in stage I lung adenocarcinoma patients. Int J Clin Exp Pathol 8: 8252-8259, 2015.

53. Wang M, Feng L, Li P, Han N, Gao Y and Xiao T: Hsp90AB1 protein is overexpressed in non-small cell lung cancer tissues and associated with poor prognosis in lung adenocarcinoma patients. Zhongguo Fei Ai Za Zhi 19: 64-69, 2016 (In Chinese).

54. Shi Y, Liu X, Lou J, Han X, Zhang L, Wang Q, Li B, Dong M and Zhang Y: Plasma levels of heat shock protein 90 alpha associated with lung cancer development and treatment responses. Clin Cancer Res 20: 6016-6022, 2014

55. Wang YQ, Shen AJ, Sun JY, Wang X, Liu HC, Zhang MM, Chen DQ, Xiong B, Shen JK, Geng MY, et al: Targeting Hsp90 with FS-108 circumvents gefitinib resistance in EGFR mutant non-small cell lung cancer cells. Acta Pharmacol Sin 37: 1587-1596, 2016.

56. Gaponova AV, Nikonova AS, Deneka AY,Kopp MC, Kudinov AE, Skobeleva N, Khazak V, Ogawa LS, Cai KQ, Duncan KE, et al: A novel HSP90 inhibitor-drug conjugate to SN38 is highly effective in small cell lung cancer. Clin Cancer Res 22: 5120-5129, 2016.

57. Niu B, Lin J and Feng T: Effects of 17-AAG on the proliferation and apoptosis of human lung cancer A549 and H446 cells. Zhonghua Jie He He Hu Xi Za Zhi 38: 267-272, 2015 (In Chinese).

58. Hirakawa H, Fujisawa H, Masaoka A, Noguchi M, Hirayama R, Takahashi M, Fujimori A and Okayasu R: The combination of Hsp90 inhibitor 17AAG and heavy-ion irradiation provides effective tumor control in human lung cancer cells. Cancer Med 4: 426-436, 2015 .

59. Zhang Q, Zhai S, Li L, Li X, Jiang C, Zhang C and Yan B: P-glycoprotein-evading anti-tumor activity of a novel tubulin and HSP90 dual inhibitor in a non-small-cell lung cancer model. J Pharmacol Sci 126: 66-76, 2014.

60. Normant E, Paez G, West KA, Lim AR, Slocum KL, Tunkey C, McDougall J, Wylie AA, Robison K, Caliri K, et al: The Hsp90 inhibitor IPI-504 rapidly lowers EML4-ALK levels and induces tumor regression in ALK-driven NSCLC models. Oncogene 30: 2581-2586, 2011 
61. Gallerne C, Prola A and Lemaire C: Hsp90 inhibition by PU-H71 induces apoptosis through endoplasmic reticulum stress and mitochondrial pathway in cancer cells and overcomes the resistance conferred by Bcl-2. Biochim Biophys Acta 1833: 1356-1366, 2013

62. Seo YH: Discovery of 2',4'-dimethoxychalcone as a Hsp90 inhibitor and its effect on iressa-resistant non-small cell lung cancer (NSCLC). Arch Pharm Res 38: 1783-1788, 2015.

63. Choi YJ, Kim SY, So KS, Baek IJ, Kim WS, Choi SH, Lee JC, Bivona TG, Rho JK and Choi CM: AUY922 effectively overcomes MET- and AXL-mediated resistance to EGFR-TKI in lung cancer cells. PLoS One 10: e0119832, 2015.

64. Ueno T, Tsukuda K, Toyooka S, Ando M, Takaoka M, Soh J, Asano H, Maki Y, Muraoka T, Tanaka N, et al: Strong anti-tumor effect of NVP-AUY922, a novel Hsp90 inhibitor, on non-small cell lung cancer. Lung Cancer 76: 26-31, 2012.

65. Jang WJ, Jung SK, Kang JS, Jeong JW, Bae MK, Joo SH, Park GH, Kundu JK, Hong YS and Jeong CH: Anti-tumor activity of WK88-1, a novel geldanamycin derivative, in gefitinib-resistant non-small cell lung cancers with Met amplification. Cancer Sci 105: 1245-1253, 2014

66. Smith DL, Acquaviva J, Sequeira M, Jimenez JP, Zhang C, Sang J, Bates RC and Proia DA: The HSP90 inhibitor ganetespib potentiates the antitumor activity of EGFR tyrosine kinase inhibition in mutant and wild-type non-small cell lung cancer. Target Oncol 10: 235-245, 2015.

67. Koizumi H, Yamada T, Takeuchi S, Nakagawa T, Kita K, Nakamura T, Matsumoto K, Suda K, Mitsudomi T and Yano S: Hsp90 inhibition overcomes HGF-triggering resistance to EGFR-TKIs in EGFR-mutant lung cancer by decreasing client protein expression and angiogenesis. J Thorac Oncol 7: 1078-1085, 2012

68. Kobayashi N, Toyooka S, Soh J, Yamamoto H, Dote $\mathrm{H}$, Kawasaki K, Otani H, Kubo T, Jida M, Ueno T, et al: The antiproliferative effect of heat shock protein 90 inhibitor, 17-DMAG on non-small-cell lung cancers being resistant to EGFR tyrosine kinase inhibitor. Lung Cancer 75: 161-166, 2012.

69. Rice JW, Veal JM, Barabasz A, Foley B, Fadden P, Scott A, Huang K, Steed P and Hall S: Targeting of multiple signaling pathways by the Hsp90 inhibitor SNX-2112 in EGFR resistance models as a single agent or in combination with erlotinib. Oncol Res 18: 229-242, 2009.

70. Song X, Zhao Z, Qi X, Tang S, Wang Q, Zhu T, Gu Q, Liu M and Li J: Identification of epipolythiodioxopiperazines HDN-1 and chaetocin as novel inhibitor of heat shock protein 90 . Oncotarget 6: 5263-5274, 2015

71. Park KS, Oh B, Lee MH, Nam KY, Jin HR, Yang H, Choi J, Kim SW and Lee DH: The HSP90 inhibitor, NVP-AUY922, sensitizes KRAS-mutant non-small cell lung cancer with intrinsic resistance to MEK inhibitor, trametinib. Cancer Lett 372: 75-81, 2016

72. Takeuchi S, Fukuda K, Arai S, Nanjo S, Kita K, Yamada T, Hara E, Nishihara H, Uehara $\mathrm{H}$ and Yano S: Organ-specific efficacy of HSP90 inhibitor in multiple-organ metastasis model of chemorefractory small cell lung cancer. Int J Cancer 138 : 1281-1289, 2016

73. Tung CL, Jian YJ, Syu JJ, Wang TJ, Chang PY, Chen CY, Jian YT and Lin YW: Down-regulation of ERK1/2 and AKT-mediated $\mathrm{X}$-ray repair cross-complement group 1 protein (XRCC1) expression by Hsp90 inhibition enhances the gefitinib-induced cytotoxicity in human lung cancer cells. Exp Cell Res 334 126-135, 2015.

74. Tung CL, Chiu HC, Jian YJ, Jian YT, Chen CY, Syu JJ, Wo TY, Huang YJ, Tseng SC and Lin YW: Down-regulation of MSH2 expression by an Hsp90 inhibitor enhances pemetrexed-induced cytotoxicity in human non-small-cell lung cancer cells. Exp Cell Res 322: 345-354, 2014.

75. Weng SH, Tseng SC, Huang YC, Chen HJ and Lin YW: Inhibition of thymidine phosphorylase expression by using an HSP90 inhibitor potentiates the cytotoxic effect of cisplatin in nonsmall-cell lung cancer cells. Biochem Pharmacol 84: 126-136, 2012.

76. Bao R, Lai CJ, Wang DG, Qu H, Yin L, Zifcak B, Tao X, Wang J, Atoyan R, Samson M, et al: Targeting heat shock protein 90 with CUDC-305 overcomes erlotinib resistance in non-small cell lung cancer. Mol Cancer Ther 8: 3296-3306, 2009.

77. Kim WY, Chang DJ, Hennessy B, Kang HJ, Yoo J, Han SH, Kim YS, Park HJ, Seo SY, Mills G, et al: A novel derivative of the natural agent deguelin for cancer chemoprevention and therapy. Cancer Prev Res (Phila) 1: 577-587, 2008.
78. Lee SC, Min HY, Choi H, Kim HS, Kim KC, Park SJ, Seong MA, Seo JH, Park HJ, Suh YG, et al: Synthesis and evaluation of a novel deguelin derivative, L80, which disrupts ATP binding to the C-terminal domain of heat shock protein 90. Mol Pharmacol 88: 245-255, 2015

79. Ono N, Yamazaki T, Tsukaguchi T, Fujii T, Sakata K, Suda A, Tsukuda T, Mio T, Ishii N, Kondoh O, et al: Enhanced antitumor activity of erlotinib in combination with the Hsp90 inhibitor CH5164840 against non-small-cell lung cancer. Cancer Sci 104: 1346-1352, 2013

80. Ko JC, Chen HJ, Huang YC, Tseng SC, Weng SH, Wo TY, Huang YJ, Chiu HC, Tsai MS, Chiou RY, et al: HSP90 inhibition induces cytotoxicity via down-regulation of Rad51 expression and DNA repair capacity in non-small cell lung cancer cells. Regul Toxicol Pharmacol 64: 415-424, 2012.

81. Acquaviva J, Smith DL, Sang J, Friedland JC, He S, Sequeira M, Zhang C, Wada Y and Proia DA: Targeting KRAS-mutant non-small cell lung cancer with the Hsp90 inhibitor ganetespib. Mol Cancer Ther 11: 2633-2643, 2012.

82. Ko JC, Chiu HC, Syu JJ, Chen CY, Jian YT, Huang YJ, Wo TY, Jian YJ, Chang PY, Wang TJ, et al: Down-regulation of MSH2 expression by Hsp90 inhibition enhances cytotoxicity affected by tamoxifen in human lung cancer cells. Biochem Biophys Res Commun 456: 506-512, 2015

83. Lee KH, Jang AH and Yoo CG: 17-allylamino-17-demethoxygeldanamycin and the enhancement of PS-341-induced lung cancer cell death by blocking the NF-kappaB and PI3K/Akt pathways. Am J Respir Cell Mol Biol 53: 412-421, 2015.

84. Qu Z, Dong H, Xu X, Feng W and Yi X: Combined effects of 17-DMAG and TNF on cells through a mechanism related to the NF-kappaB pathway. Diagn Pathol 8: 70, 2013.

85. Sang J, Acquaviva J, Friedland JC, Smith DL, Sequeira M, Zhang C, Jiang Q, Xue L, Lovly CM, Jimenez JP, et al: Targeted inhibition of the molecular chaperone Hsp90 overcomes ALK inhibitor resistance in non-small cell lung cancer. Cancer Discov 3: 430-443, 2013

86. Garon EB, Finn RS, Hamidi H, Dering J, Pitts S, Kamranpour N, Desai AJ, Hosmer W, Ide S, Avsar E, et al: The HSP90 inhibitor NVP-AUY922 potently inhibits non-small cell lung cancer growth. Mol Cancer Ther 12: 890-900, 2013

87. Wang Q, Sun W, Hao X, Li T, Su L and Liu X: Down-regulation of cellular FLICE-inhibitory protein (Long Form) contributes to apoptosis induced by Hsp90 inhibition in human lung cancer cells. Cancer Cell Int 12: 54, 2012.

88. Shimamura T, Perera SA, Foley KP, Sang J, Rodig SJ, Inoue T, Chen L, Li D, Carretero J, Li YC, et al: Ganetespib (STA-9090), a nongeldanamycin HSP90 inhibitor, has potent antitumor activity in in vitro and in vivo models of non-small cell lung cancer. Clin Cancer Res 18: 4973-4985, 2012.

89. Oh SH, Woo JK, Yazici YD, Myers JN, Kim WY, Jin Q, Hong SS, Park HJ, Suh YG, Kim KW, et al: Structural basis for depletion of heat shock protein 90 client proteins by deguelin. J Natl Cancer Inst 99: 949-961, 2007.

90. Wang X, Ju W, Renouard J, Aden J, Belinsky SA and Lin Y: 17-allylamino-17-demethoxygeldanamycin synergistically potentiates tumor necrosis factor-induced lung cancer cell death by blocking the nuclear factor-kappaB pathway. Cancer Res 66: 1089-1095, 2006.

91. Wang Y, Liu H, Diao L, Potter A, Zhang J, Qiao Y, Wang J, Proia DA, Tailor R, Komaki R, et al: Hsp90 inhibitor ganetespib sensitizes non-small cell lung cancer to radiation but has variable effects with chemoradiation. Clin Cancer Res 22: 5876-5886, 2016.

92. Segawa T, Fujii Y, Tanaka A, Bando S, Okayasu R, Ohnishi K and Kubota N: Radiosensitization of human lung cancer cells by the novel purine-scaffold Hsp90 inhibitor, PU-H71. Int J Mol Med 33: 559-564, 2014.

93. Camphausen K and Tofilon PJ: Inhibition of Hsp90: A multitarget approach to radiosensitization. Clin Cancer Res 13: 4326-4330, 2007.

94. Koll TT, Feis SS, Wright MH, Teniola MM, Richardson MM, Robles AI, Bradsher J, Capala J and Varticovski L: HSP90 inhibitor, DMAG, synergizes with radiation of lung cancer cells by interfering with base excision and ATM-mediated DNA repair. Mol Cancer Ther 7: 1985-1992, 2008.

95. Laszlo A, Thotala D and Hallahan DE: Membrane phospholipids, EML4-ALK, and Hsp90 as novel targets in lung cancer treatment. Cancer J 19: 238-246, 2013.

96. Schilling D, Bayer C, Li W, Molls M, Vaupel P and Multhoff G: Radiosensitization of normoxic and hypoxic h1339 lung tumor cells by heat shock protein 90 inhibition is independent of hypoxia inducible factor-1 $\alpha$. PLoS One 7: e31110, 2012. 
97. Lee JH, Choi KJ, Seo WD, Jang SY, Kim M, Lee BW, Kim JY, Kang S, Park KH, Lee YS, et al: Enhancement of radiation sensitivity in lung cancer cells by celastrol is mediated by inhibition of Hsp90. Int J Mol Med 27: 441-446, 2011.

98. Kim WY, Oh SH, Woo JK, Hong WK and Lee HY: Targeting heat shock protein 90 overrides the resistance of lung cancer cells by blocking radiation-induced stabilization of hypoxiainducible factor-lalpha. Cancer Res 69: 1624-1632, 2009.

99. Beck TN, Korobeynikov VA, Kudinov AE, Georgopoulos R, Solanki NR, Andrews-Hoke M, Kistner TM, Pépin DPK, Nicolas E, et al: Anti-Müllerian hormone signaling regulates epithelial plasticity and chemoresistance in lung cancer. Cell Rep 16: 657-671, 2016

100. Proia DA, Sang J, He S, Smith DL, Sequeira M, Zhang C, Liu Y, Ye S, Zhou D, Blackman RK, et al: Synergistic activity of the Hsp90 inhibitor ganetespib with taxanes in non-small cell lung cancer models. Invest New Drugs 30: 2201-2209, 2012.

101. Tsai MS, Weng SH, Chen HJ, Chiu YF, Huang YC, Tseng SC, Kuo YH and Lin YW: Inhibition of p38 MAPK-dependent excision repair cross-complementing 1 expression decreases the DNA repair capacity to sensitize lung cancer cells to etoposide. Mol Cancer Ther 11: 561-571, 2012.

102. Hashida S, Yamamoto H, Shien K, Ohtsuka T, Suzawa K, Maki Y, Furukawa M, Soh J, Asano H, Tsukuda K, et al: Hsp90 inhibitor NVP-AUY922 enhances the radiation sensitivity of lung cancer cell lines with acquired resistance to EGFR-tyrosine kinase inhibitors. Oncol Rep 33: 1499-1504, 2015.

103. Sawai A, Chandarlapaty S, Greulich H, Gonen M, Ye Q Arteaga CL, Sellers W, Rosen N and Solit DB: Inhibition of Hsp90 down-regulates mutant epidermal growth factor receptor (EGFR) expression and sensitizes EGFR mutant tumors to paclitaxel. Cancer Res 68: 589-596, 2008.

104. Lee SC, Min HY, Choi H, Bae SY, Park KH, Hyun SY, Lee HJ, Moon J, Park SH, Kim JY, et al: Deguelin analogue SH-1242 inhibits Hsp90 activity and exerts potent anticancer efficacy with limited neurotoxicity. Cancer Res 76: 686-699, 2016.
105. Yang YC, Cheng TY, Huang SM, Su CY, Yang PW, Lee JM, Chen CK, Hsiao M, Hua KT and Kuo ML: Cytosolic PKM2 stabilizes mutant EGFR protein expression through regulating Hsp90-EGFR association. Oncogene 35: 3387-3398, 2016.

106. Chen Z, Akbay E, Mikse O, Tupper T, Cheng K, Wang Y, Tan X, Altabef A, Woo SA, Chen L, et al: Co-clinical trials demonstrate superiority of crizotinib to chemotherapy in ALK-rearranged non-small cell lung cancer and predict strategies to overcome resistance. Clin Cancer Res 20: 1204-1211, 2014.

107. Tanimoto A, Yamada T, Nanjo S, Takeuchi S, Ebi H, Kita K, Matsumoto K and Yano S: Receptor ligand-triggered resistance to alectinib and its circumvention by Hsp90 inhibition in EML4-ALK lung cancer cells. Oncotarget 5: 4920-4928, 2014.

108. Rolfo C, Passiglia F, Castiglia M, Raez LE, Germonpre P, Gil-Bazo I, Zwaenepoel K, De Wilde A, Bronte G, Russo A, et al: ALK and crizotinib: After the honeymoon...what else? Resistance mechanisms and new therapies to overcome it. Transl Lung Cancer Res 3: 250-261, 2014.

109. Ramalingam S, Goss G, Rosell R, Schmid-Bindert G, Zaric B, Andric Z, Bondarenko I, Komov D, Ceric T, Khuri F, et al: A randomized phase II study of ganetespib, a heat shock protein 90 inhibitor, in combination with docetaxel in second-line therapy of advanced non-small cell lung cancer (GALAXY-1). Ann Oncol 26: 1741-1748, 2015.

110. Socinski MA, Goldman J, El-Hariry I, Koczywas M, Vukovic V, Horn L, Paschold E, Salgia R, West H, Sequist LV, et al: A multicenter phase II study of ganetespib monotherapy in patients with genotypically defined advanced non-small cell lung cancer. Clin Cancer Res 19: 3068-3077, 2013.

111. Sequist LV, Gettinger S, Senzer NN, Martins RG, Jänne PA, Lilenbaum R, Gray JE, Iafrate AJ, Katayama R, Hafeez N, et al: Activity of IPI-504, a novel heat-shock protein 90 inhibitor, in patients with molecularly defined non-small-cell lung cancer. J Clin Oncol 28: 4953-4960, 2010. 